\title{
REVIEWS
}

Check for updates

\section{B cell depletion therapies in autoimmune disease: advances and mechanistic insights}

\section{Dennis S. W. Lee ${ }^{1,2}$, Olga L. Rojas $\mathbb{1}^{1,2}$ and Jennifer L. Gommerman $\mathbb{1}^{1 凶}$}

Abstract | In the past 15 years, B cells have been rediscovered to be not merely bystanders but rather active participants in autoimmune aetiology. This has been fuelled in part by the clinical success of $B$ cell depletion therapies (BCDTs). Originally conceived as a method of eliminating cancerous $B$ cells, BCDTs such as those targeting CD20, CD19 and BAFF are now used to treat autoimmune diseases, including systemic lupus erythematosus and multiple sclerosis. The use of BCDTs in autoimmune disease has led to some surprises. For example, although antibody-secreting plasma cells are thought to have a negative pathogenic role in autoimmune disease, BCDT, even when it controls the disease, has limited impact on these cells and on antibody levels. In this Review, we update our understanding of B cell biology, review the results of clinical trials using BCDT in autoimmune indications, discuss hypotheses for the mechanism of action of BCDT and speculate on evolving strategies for targeting $B$ cells beyond depletion.

\section{CD40 ligand}

(CD40L). Also known as

CD154 or TNFSF5, a member of the tumour necrosis factor (TNF) superfamily. Expression of CD40L by Thelper cells is a key ingredient for a functional T cell-dependent germinal centre response through stimulation of $\mathrm{CD} 40$ on $\mathrm{B}$ cells.
'Department of Immunology, University of Toronto, Toronto, ON, Canada.

${ }^{2}$ These authors contributed equally: Dennis S. W. Lee, Olga L. Rojas.

凶e-mail:jen.gommerman@ utoronto.ca

https://doi.org/10.1038/ s41573-020-00092-2
B cells, along with T cells, form the core of the adaptive arm of the immune system. They are generated continually and throughout the life of the organism in the bone marrow, a primary lymphoid tissue, from haematopoietic stem cell progenitors that progress through sequential developmental steps. Each developing B cell expresses a unique $\mathrm{B}$ cell receptor (BCR), which is composed of two identical heavy chain proteins and two identical light chain proteins. In both humans and rodents, once a developing B cell expresses a correctly assembled BCR on its cell surface, and that BCR has been confirmed to not be autoreactive, the $\mathrm{IgM}^{+}$immature $\mathrm{B}$ cell exits the bone marrow, enters the blood and migrates to the spleen.

Within the spleen, the architecture of which is somewhat different in mice versus humans ${ }^{1}$, immature B cells undergo additional developmental steps (BOX 1; FIC. 1). The immature $\mathrm{B}$ cell is then considered a naive $\mathrm{B}$ cell (NBC), which has the capacity to be primed against proteins derived from foreign pathogens (that is, antigens). With a half-life of approximately 6 weeks, the NBCs circulate in the blood and enter lymph node organs through high endothelial venules. Unless they are activated by an antigen, B cells will spend approximately 24 hours in follicles, which are structures found in the lymph node cortex. They are drawn to these structures because NBCs express CXC-chemokine receptor 5 (CXCR5), which binds to its ligand, CXC-chemokine ligand 13 (CXCL13); CXCL13 is expressed in the follicle. Following this brief residence in the follicle, NBCs follow the gradient of a different molecule, sphingosine 1-phosphate, to the medullary cords and out through the efferent lymphatics. After transitioning through the thoracic duct, NBCs re-enter the blood and repeat this journey ${ }^{2}$.

Because of the remarkable diversity of the BCR repertoire, $B$ cells can respond to a seemingly infinite number of antigens. Immune responses to antigens occur within secondary lymphoid organs (lymph nodes, tonsils and spleen): the spleen supports immune responses to blood-borne antigens, whereas lymph nodes sample tissue-derived antigens ${ }^{3}$. Binding of an antigen to the BCR results in intracellular events such as calcium mobilization and protein phosphorylation ${ }^{4}$.

Depending on the molecular structure of the antigen, NBCs may or may not need additional help from $\mathrm{T}$ cells to fully respond to the antigen. To induce this help, B cells that have been activated by particular protein antigens form cognate interactions with $\mathrm{T}$ cells that are specific for a linear peptide fragment of the same antigen. These cognate B cell-T cell interactions occur in the germinal centres (GCs) in secondary lymphoid organs. Within the GCs, B cells with a range of affinities for the antigen compete for help from these cognate $\mathrm{T}$ cells, which express key costimulatory proteins, such as CD40 ligand (CD40L), and also make cytokines that direct the $\mathrm{B}$ cell response.

To increase their affinity for antigens, B cells also undergo secondary BCR diversification. The BCRencoding genes accumulate mutations in their antigenbinding regions through the activity of activation-induced 
Class switch recombination The rearrangement of constant regions at the immunoglobulin heavy chain locus. This results in the splicing out of one constant region for a different one downstream of the original and, consequently, the expression of a different antibody class (that is, IgC instead of lgM).

T follicular helper cells ( $\mathrm{T}_{\mathrm{FH}}$ cells). A specialized subset of $\mathrm{T}$ cells that express CXC-chemokine receptor 5 (CXCR5), enabling them to enter CXC-chemokine ligand 13 (CXCL13)-rich B cell follicles to help $\mathrm{B}$ cell responses.

Regulatory $\mathrm{T}_{\mathrm{FH}}$ cells A specialized subset of $\mathrm{T}$ cells that also express CXC-chemokine receptor 5 (CXCR5) and regulate $\mathrm{T}$ follicular helper cells ( $\mathrm{T}_{\mathrm{rH}}$ cells) by their expression of co-inhibitory molecules (for example, CTLA4) and inhibitor cytokines (for example, IL-10).

BAFF

A member of the tumour necrosis factor (TNF) superfamily. BAFF is a critical survival cytokine for B cells as well as plasmablasts and plasma cells. cytidine deaminase (AID). This process results in multiple variants of the original germ line BCR, and the $\mathrm{B}$ cells that emerge from this mutagenesis programme with the highest affinity for the antigen will 'win' the GC reaction competition and become dominant clones in the immune response ${ }^{5}$. Such B cells can also undergo class switch recombination to generate B cells that produce other classes of antibodies. A proportion of these B cells (switched and unswitched) become memory B cells (MBCs) or plasma cells (PCs), which secrete copious amounts of antibodies. MBCs and long-lived PCs (LLPCs) provide protection against reinfection by the same pathogen ${ }^{6}$.

Due to their vigorous proliferation and the accompanying mutagenesis programme, GC B cells can be vulnerable to cancerous transformation. For this reason, reagents that bind surface glycoproteins expressed by B cells such as CD20 have been successfully used to target B cell lymphomas for depletion, removing both cancerous and non-cancerous $\mathrm{CD} 20^{+} \mathrm{B}$ cells from the patient ${ }^{7}$. Given the excellent safety profile of many B cell depletion therapies (BCDTs) in cancer ${ }^{8}$, these drugs were reimagined for use in autoimmune diseases in which B cells play a direct or indirect role.

We begin this Review with select recent advances in $\mathrm{B}$ cell biology that are relevant to the mechanism of action of BCDT in autoimmune disease. Then we outline the clinical results from disease settings in which BCDTs have been used extensively — such as systemic lupus erythematosus (SLE), rheumatoid arthritis (RA) and multiple sclerosis (MS) - and discuss some emerging indications that may benefit from BCDT. Lastly, we discuss the potential mechanism of action of BCDT, possible reasons why BCDT has failed in some indications,

\section{Box $1 \mid$ B cell development}

Conventional $B$ cells originate in the bone marrow and express a $B$ cell receptor (BCR) that is generated through random recombination of heavy and light chain genes to form a unique BCR. If this BCR on immature B cells in the bone marrow has high affinity for a self-antigen, receptor editing may occur whereby the light chain is swapped for another. Central tolerance (in the bone marrow and thymus) and peripheral tolerance (in the spleen) are the two major tolerance checkpoints for developing B cells. The mechanisms that induce tolerance include clonal deletion, clonal unresponsiveness to an antigen (anergy) and receptor editing. The latter is thought to be the main mechanism of B cell tolerance and involves secondary immunoglobulin gene rearrangements, primarily at the $\kappa$-locus ${ }^{277,278}$. Immature B cells that pass these tolerance checkpoints exit the bone marrow as transitional $B$ cells. Repopulation studies of the $B$ cell compartment in patients treated with anti-CD20 B cell depletion therapy (BCDT) have identified three subsets of transitional $\mathrm{B}$ cells $(\mathrm{T} 1, \mathrm{~T} 2 \text { and } \mathrm{T} 3)^{279}$. The maturation through transitional stages is marked by the loss of CD5 and CD10, reduction in surface lgM levels and the upregulation of CD22, CD44, CD21 and CD23.

On the basis of mouse studies, there are two types of B cells: B1 cells, which originate from fetal precursors, predominantly localize to peritoneal and pleural cavities and are considered 'natural or innate' B cells; and conventional B2 cells, which originate in the bone marrow, circulate through the blood and secondary lymphoid tissues and participate in the adaptive humoral immune response against pathogens. A recently identified $\mathrm{CD} 20^{+} \mathrm{CD} 27^{+} \mathrm{CD} 43^{+} \mathrm{CD} 70^{-}$circulating $\mathrm{B}$ cell may be a human $\mathrm{B} 1$ equivalent on the basis of functional readouts, which include spontaneous $\lg M$ secretion and constitutive BCR signalling ${ }^{280}$, although this has been disputed ${ }^{281}$. These putative blood B1 cells exhibit gene expression patterns that resemble those of memory B cells, selectively produce anti-phosphoryl choline $\lg \mathrm{M}$ and have a tendency to use $\mathrm{VH}$ genes that are associated with autoreactivity ${ }^{282}$. When the impact of anti-CD20 BCDT is being considered, these cells should be taken into account.

and some new therapeutic directions for BCDT based on recent advances in B cell biology.

\section{Recent advances in B cell biology}

To understand how BCDT works in autoimmune disease, and to design superior B cell-targeted therapies, we must first understand some fundamental aspects of $\mathrm{B}$ cell biology. The topic of how BCDT impacts autoimmune disease was last reviewed in this journal in 2006 (REF.'); much has changed since then. Here, we note some highlights from the literature that are relevant to the use of BCDT in treating autoimmune disease.

Activation of B cells. The GC is an important microenvironment that supports the interaction of antigen-specific $\mathrm{B}$ and T cells. GCs are readily observed in histological sections of secondary lymphoid organs (tonsils, spleen and lymph nodes) in mice and humans. Somatic hypermutation mediated by AID may increase the affinity of the BCR, but may also reduce its affinity, or even generate an affinity for self-antigen. Due to its anatomical organization (BOX 2), the GC environment imposes a framework of competition among GC-resident B cells such that those B cells with the highest affinity for an antigen persist and become MBCs and PCs. Advances in our understanding of this GC reaction may inform the design of specific therapies that interfere with this specialized microenvironment. For example, in the past 10 years, our understanding of how $\mathrm{T}$ follicular helper cells ( $\mathrm{T}_{\mathrm{FH}}$ cells) and regulatory $\mathrm{T}_{\mathrm{FH}}$ cells engage with $\mathrm{B}$ cells has exploded ${ }^{10}$. In mouse models, entanglement of GC-resident $\mathrm{T}_{\mathrm{FH}}$ cells with GC B cells promotes sustained interactions that select for B cells with the highest affinity for an antigen through a process of feedforward loops involving CD40L, inducible T cell costimulator (ICOS) and BAFF (also known as TNFSF13B) ${ }^{11}$. This entanglement is reminiscent of the types of CD40-CD40L-driven $\mathrm{B}$ cell-T cell interactions that occur in human tonsils ${ }^{12}$. Although beyond the scope of this Review, removing or disabling $\mathrm{T}_{\mathrm{FH}}$ cells to prevent the $\mathrm{GC}$ reaction is a possible strategy for treating autoimmune disease.

The GC is not the only environment in which B cells can participate in the immune response. Extrafollicular $B$ cell responses provide an early source of antibodies during infection ${ }^{13}$. In mouse models, antigen-specific $B$ cells destined for the extrafollicular response maintain high levels of EBI2 (also known as GPR183) expression, which keeps these cells out of the GC microenvironment, and upregulate CXCR4, which allows them to localize to the medullary cords of the lymph nodes ${ }^{14,15}$. Although initially considered to be T cell-independent $\mathrm{B}$ cell responses, we now know that extrafollicular responses recruit $\mathrm{T}_{\mathrm{FH}}$ cells ${ }^{16}$. Moreover, the extrafollicular response can foster somatic hypermutation, as has been shown in infection models such as Salmonella enterica subsp. enterica serovar Typhimurium infection, in which GC responses are rare $^{17}$. In addition to these mouse studies, extrafollicular class switching, driven by the cytokines BAFF and APRIL (also known as TNFSF13), has been documented in human tonsils and gut $^{18,19}$. Extrafollicular B cell responses have also been observed in the synovium and salivary glands of patients 

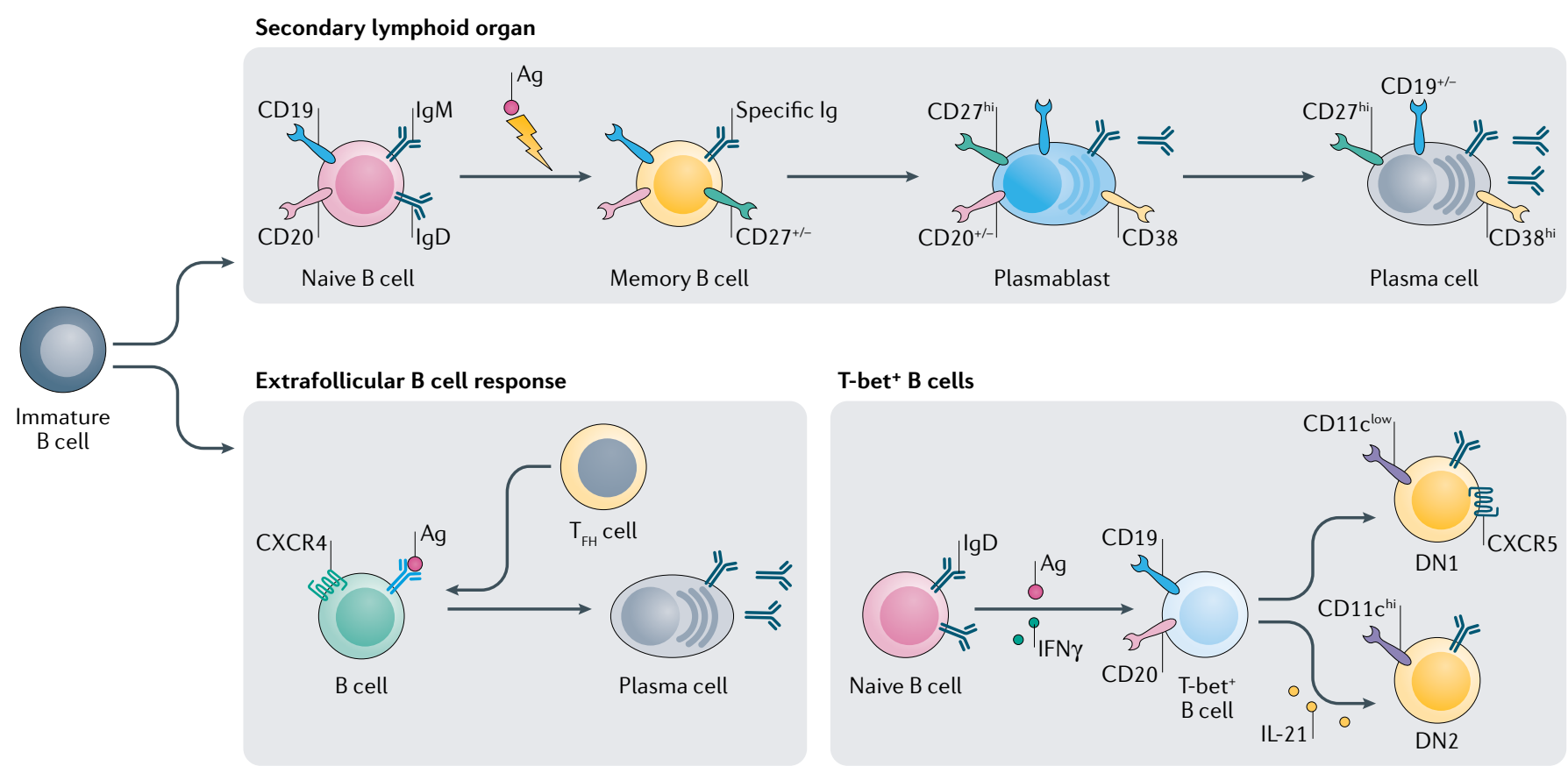

Fig. 1 | B cell biology. Following their development in the bone marrow, immature B cells enter the circulation and complete their development in the spleen. In the spleen, they first become naive B cells (NBCs). If activated by an antigen (Ag), NBCs may then enter an emerging germinal centre (GC), where affinity maturation occurs. The highest-affinity B cells emerge from the GC as memory B cells or plasma cells. Some NBCs can also be activated in extrafollicular environments, for example in the T cell area or in the medullary cords. NBCs activated in extrafollicular environments quickly become plasma cells. In the presence of IFN $\gamma$, B cells also can also acquire the expression of T-bet, and some T-bet ${ }^{+}$cells will remain in the spleen as memory B cells. Some T-bet ${ }^{+}$cells can adopt a double-negative 1 (DN1) or DN2 phenotype, with the latter being influenced by cytokines such as IL-21. CXCR, CXC-chemokine receptor; Ig, immunoglobulin; $\mathrm{T}_{\mathrm{FH}}$ cell, $\mathrm{T}$ follicular helper cell.

with RA or Sjögren syndrome ${ }^{20-23}$. The extrafollicular pathway of B cell activation is also an early and potent source of PCs because BLIMP1 (also known as PRDM1) is rapidly upregulated in extrafollicular B cells. When expressed in B cells, BLIMP1 represses the expression of genes involved in BCR signalling and GC B cell function, so cells adopt a PC phenotype p $^{24}$.

Extrafollicular responses have implications for autoimmune diseases. Indeed, in MRL/FAS ${ }^{\mathrm{lpr}}$ mice, a model for SLE, autoreactive plasmablasts (PBs) are generated not within the follicle or the GC but rather in T cell-rich areas of lymphoid tissues ${ }^{25,26}$. Moreover, in other lupus-prone mouse models, autoreactive antibody-producing B cells can be generated in extrafollicular regions independently of T cells; B cell survival factors such as BAFF and pattern recognition receptors such as Toll-like receptor 7 (TLR7) play important roles in the generation of these B cells ${ }^{27,28}$. Although extrafollicular responses clearly produce class-switched B cells, in contrast, and in keeping with older findings in the literature, GCs are dominated by non-class-switched $\operatorname{IgM}^{+}$ $B$ cells in mice and humans ${ }^{29}$. Since class-switched antibodies are critical in the pathogenesis of diseases such as SLE, this observation calls into question the utility of targeting the GC itself as a therapeutic strategy.

In humans, it is difficult to study the extrafollicular response because tissue is not readily available. However, some inferences may be made from clinical observations. For example, so-called monocytoid
B cells, which express CD19 but have a monocyte-like morphology, have been found in lymph node sinusoidal spaces, and the expression of AID in these cells suggests that an extrafollicular response may be occurring ${ }^{30}$. Moreover, B cells associated with the tonsillar epithelium can undergo class switch to IgG and IgA and undergo somatic hypermutation in response to locally produced cytokines, again suggesting an extrafollicular response ${ }^{18}$. For the most part, however, extrafollicular responses in humans are inferred because some circulating MBCs are $\mathrm{CXCR}^{-}$and have relatively low levels of somatic hypermutation of the BCR, suggesting that they matured outside the $\mathrm{GC}^{31}$.

From these findings taken together, although we traditionally think of GCs as a hotbed for autoimmune $\mathrm{B}$ cell genesis, targeting extrafollicular responses may also have significant utility in treating B cell-mediated autoimmune diseases.

T-bet ${ }^{+} \boldsymbol{B}$ cells. Multiple B cell subsets have been described in the past decade. Of these, B cells that express T-bet (also known as TBX21) may play a particularly important role in autoimmune diseases. T-bet is a transcription factor that historically has been considered a hallmark of IFN $\gamma$-producing T helper 1 cells. However, T-bet can also be expressed in B cells ${ }^{32}$, and even in dendritic cells $\mathrm{s}^{33}$, in both mice and humans. T-bet ${ }^{+} \mathrm{B}$ cells are commonly referred to as double-negative (DN) B cells, as they express neither CD27 (also known as TNFRSF7) 


\section{Box 2 | Organization of GCs}

From classic histology studies, we know that the human germinal centre (GC) is divided into a light zone and a dark zone. The dark zone contains rapidly proliferating and densely packed centroblast $B$ cells that have upregulated activation-induced cytidine deaminase (AID), and are thus actively undergoing somatic hypermutation. The dark zone provides a source of $B$ cells that continuously enter the light zone for subsequent selection events. Within the light zone, centrocyte GC B cells undergo antigendriven selection, and in this location GC B cells obtain help from T cells, with the best cognate interactions between $B$ and T cells 'winning' interclonal competitions.

More recently we have learned that, in lymph nodes, non-cognate $B$ cells serve as a bridge for transporting antigens from subcapsular sinus macrophages to follicular dendritic cells (FDCs), which are located within the B cell follicle in the cortex of the lymph node ${ }^{283,284}$. Antigens displayed by FDCs in the light zone can persist for long periods as complement-coated antigens are shuttled between endosomes and the surface of $\mathrm{FDCs}^{285}$. For antigen-specific $\mathrm{B}$ cells to reach these FDC-containing GCs, duelling chemokine axes that activate G-protein-coupled receptors guide this migration event. EBI2 (also known as GPR183), which is the receptor for 7a,25-dihydroxycholesterol, normally constrains $B$ cells to the outer follicle. This receptor is downregulated in antigen-activated B cells, so they migrate deeper into the follicle towards the $\mathrm{GC}^{286-288}$. Meanwhile, sphingosine 1-phosphate restrains GC B cells from migrating towards the outer follicle ${ }^{289}$; in the case of human GC B cells, this occurs in concert with activation of P2RY8, another G protein-coupled receptor ${ }^{290}$. nor IgD. Although DN B cells are CD27-, and CD27 usually marks MBCs, DN B cells are considered to be antigen-experienced ${ }^{34}$ (BOX 3).

$\mathrm{DN} B$ cells are further divided into DN1 and DN2 subsets. B cells that express high levels of T-bet (T-bet ${ }^{\text {hi }}$ $B$ cells) can be directly generated from NBC precursors in response to IFN $\gamma$ (which is locally produced by T cells) ${ }^{35}$, and consequently become 'activated naive' or DN1 $\mathrm{B}$ cells ${ }^{36}$. In addition, some T-bet ${ }^{\text {hi }} \mathrm{B}$ cells have the capacity to quickly differentiate into PCs in an IL-21-dependent manner in patients with $\mathrm{SLE}^{37}$. These B cells are DN2 cells. Importantly, DN2 cells also lack CXCR5, and thus extrafollicular responses may have contributed to their generation ${ }^{38}$. As discussed in subsequent sections, T-bet ${ }^{\text {hi }}$ DN1 and DN2 cells are enriched in patients with SLE. Because of their propensity to rapidly differentiate into antibody-secreting cells in response to cytokines, T-bet ${ }^{\text {hi }}$ DN2 cells could be a source of surges of autoantibodies, whether directly pathogenic or a reflection of generalized B cell activation.

Levels of T-bet can also be used to distinguish MBCs that recirculate (T-bet ${ }^{\text {low }}$ or $\mathrm{T}$-bet ${ }^{-}$) from those that are spleen resident and excluded from lymphatics (T-bet ${ }^{\text {hi }}$ ) in mice and humans. Both subsets arise from antigen-activated NBCs, but subsequently diverge $\mathrm{e}^{39}$. Of note, in mice, T-bet ${ }^{\mathrm{hi}} \mathrm{MBC}$ accumulate with age $\mathrm{e}^{40,41}$ and in autoimmune diseases such as $\mathrm{MS}^{42}$, and could therefore contribute to disease chronicity, particularly in aged patients. Although more research is required to understand whether T-bet ${ }^{\text {hi }}$ MBCs have a propensity to promote autoimmune disease pathology, they deserve some consideration in particular because many T-bet ${ }^{\text {hi }}$ MBCs do not circulate. Hence, we do not know whether they are depleted by anti-CD20 or anti-CD19 $\left(R^{2}{ }^{39}\right)$, although the few that do circulate are sensitive to BAFF inhibition ${ }^{43}$. Thus, the very large population of MBCs that reside within the spleen (and possibly other tissues, as has been observed in chronic infections) may not be fully depleted, especially if they reside in vasculature-poor regions ${ }^{44}$. Such spleen-resident MBCs may be especially pathogenic in autoimmune conditions, particularly in aged individuals.

Antibody-independent B cell functions. Patients who positively respond to BCDT do not necessarily show a corresponding decrease in autoantibody levels. This effect has been observed in $\mathrm{SLE}^{45}, \mathrm{MS}^{46}$ and $\mathrm{RA}^{47,48}$. In such cases, BCDT must therefore alter autoimmune diseases in a manner that is independent of antibody production. In this section, we provide evidence that $\mathrm{B}$ cells can be a potent source of cytokines that may influence autoimmune pathology. However, B cells can also act as antigen-presenting cells, and this has been intensively studied in the context of MS.

Most of our evidence that B cells can make cytokines comes from animal models in which gain-of-function and loss-of-function approaches have been used to query whether B cells are necessary and/or sufficient for providing a particular cytokine. One antibody-independent function of B cells is to initiate and/or sustain tertiary lymphoid tissues (TLTs) in inflamed tissues. In mice, TLTs have been observed in a number of autoimmune disease settings and in some cases can be driven by the membrane-bound expression of lymphotoxin- $\alpha \beta(\operatorname{LT} \alpha \beta)$ by $\mathrm{B}$ cells ${ }^{49}$, although other cell types and other cytokines (IL-17 and IL-22) can also provide this signal.

Beyond their function in TLT formation, B cells produce numerous soluble cytokines. For example, B cells can be an important source of IL-2 $\left(\right.$ REFS $\left.^{50,51}\right)$, TNF and CCL3 $\left(\mathrm{REF}^{52}\right)$ in parasite infections. In addition, although IFN $\gamma$ is typically associated with Thelper 1 cell responses, this cytokine can also be produced by B cells during bacterial infection ${ }^{53-56}$. It is not entirely clear how $\mathrm{B}$ cells are induced to make IFN $\gamma$. It may be tied to downregulation of the expression of the MHC class I receptor LY49G2 on B cells ${ }^{57}$, or in response to cytokines such as IL-27, IL-12 and IL-18 (REF. ${ }^{58}$ ). In addition to IFN $\gamma$, the proinflammatory cytokines IL- 6 and granulocytemacrophage colony-stimulating factor (GM-CSF) are produced by $\mathrm{B}$ cells during neuroinflammation in mice, as well as in humans $s^{59,60}$.

PCs are also important cytokine-producing B cells. For instance, innate response activator (IRA) B cells have been described in mice: these cells have a phenotype that is similar to PCs expressing syndecan 1 (also known as CD138), and IRA B cells can produce GM-CSF ${ }^{61}$. Moreover IL-17, which is typically produced by Thelper 17 cells, can also be produced by both mouse and human $\mathrm{PBs}$ and $\mathrm{PCs}^{62}$. In mice, $\mathrm{PBs}$ and PCs that produce GM-CSF are thought to be derived from peritoneal cavity $\mathrm{B}-1$ cells (BOX 1) that migrate to the spleen, where they produce IgM. In contrast, IL-17 is produced directly by PCs in the spleen upon infection with Trypanosoma cruzi $^{61,62}$. IgA-producing PCs in the mouse intestine can express either TNF or inducible nitrogen oxide synthase (iNOS), and this expression is required for resolution of Citrobacter rodentium infection ${ }^{63}$. PC-derived iNOS, which is induced by the unfolded protein response and contributes to PC survival ${ }^{64,65}$, also plays a role in controlling Helicobacter pylori infection in humans ${ }^{66}$. Lastly, by isolation of intestinal PCs for ex vivo flow 
Experimental autoimmune encephalomyelitis (EAE). A murine model of neuroinflammation that captures aspects of multiple sclerosis pathology. cytometry analysis and by immunofluorescence analysis on gut tissue from patients with inflammatory bowel disease, PCs in the intestine have also been shown to produce tissue-damaging molecules such as matrix metalloproteinases and granzyme B in response to inflammation ${ }^{67,68}$

In summary, these examples of alternative B cell functions beyond antibody production, including cytokine production, provide a potential explanation for the surprising efficacy of BCDT in autoimmune disease.

Regulatory B cells. B cells also have the capacity to quiet inflammation, and IL-10, which is produced by subsets of myeloid cells, B cells and T cells, clearly mediates much (but likely not all) of this anti-inflammatory effect in mice ${ }^{69}$. Again we have learned about 'unusual' B cell behaviour by studying parasitic infections in mice - in this context, IL-10 production by B cells can limit allergic responses ${ }^{70,71}$, and $\mathrm{B}$ cells can perform this function independently of regulatory $\mathrm{T}$ cells $\mathrm{s}^{9,70}$. In mice, regulatory $\mathrm{B}$ cells (which are $\mathrm{CD} 1 \mathrm{~d}^{+} \mathrm{CD}^{+}$) have been shown to produce IL-10 $\left(\mathrm{REF}^{72}\right)$ in response to both $\mathrm{CD} 40 \mathrm{~L}$ and IL-21 provided by $\mathrm{T}$ cells $\mathrm{s}^{73,74}$. IL-10-producing regulatory $\mathrm{B}$ cells have also been described in humans ${ }^{66}$. Depending on the sequence and/or nature of the activation signal, human B cells can produce IL-10 or, alternatively, secrete proinflammatory cytokines such as soluble $\mathrm{LT} \alpha_{3}$, TNF and IL-6 $\left(\mathrm{REF}^{75}\right)$. TLR signalling on B cells may also elicit different cytokine responses, for example producing either the anti-inflammatory IL-10 or the proinflammatory IL-13, depending on the type of TLR and the maturation stage of the $\mathrm{B}$ cell (NBC vs $\mathrm{MBC})^{76}$. Importantly, the ability to produce IL-10 by regulatory B cells in response to CD40 stimulation can be lost in regulatory $\mathrm{B}$ cells, as has been observed in patients with $\mathrm{SLE}^{77}$.

Anti-inflammatory cytokines can also be produced by PCs. This was clearly demonstrated in several mouse models: PCs producing IL-10 and IL-35 can attenuate neuroinflammation in experimental autoimmune encephalomyelitis $(\mathrm{EAE})^{78}$. PC-dependent IL-10 production during

\section{Box $3 \mid$ MBC heterogeneity}

The significant heterogeneity of memory $B$ cells (MBCs) has been unveiled by inventorying the transcriptional profiles of $B$ cells that meet the criteria for MBCs on the basis of their specificity, turnover characteristics and survival after exiting the germinal centre (GC). However, in determining whether a $B$ cell is an $\mathrm{MBC}$, one needs to consider attributes rather than markers - this is an important distinction that takes into account function and tissue residency. Even the assumption that CD27 (a postactivation marker) ${ }^{6}$ is present on all MBCs is fraught with difficulties as there are populations of antigen-experienced B cells that do not express CD27 (REFS ${ }^{291,292}$ ), including lgD-CD27- (double-negative) MBCs that, in some cases, are thought to be exhausted and therefore less functional in chronic infections ${ }^{293,294}$.

Heterogeneity in the MBC compartment has been parsed out nicely in the mouse system, as combinations of CD80, PDL2 and CD73 expression identify stable non-interchanging populations that differ in their levels of somatic hypermuation, propensity to express either $\operatorname{lgM}$ or $\lg \mathrm{G}$ and propensity to either form plasma cells (PCs) or re-enter the $\mathrm{GC}^{6,29}$. Expressing either the $\lg \mathrm{M}$ or the $\lg \mathrm{G}$ isotype has functional consequences for $\mathrm{MBC}$. In mouse systems, $\lg \mathrm{M}^{+} \mathrm{MBC}$ s are particularly good at responding to infectious organisms that impose evolutionary pressure on the immune system, such as Plasmodium spp., on rechallenge ${ }^{296}$. In humans, compared with $\lg ^{+} \mathrm{MBC}$, $\lg \mathrm{M}^{+} \mathrm{MBC}$ s also respond more quickly and vigorously to antigen rechallenge, tend to participate in secondary GC reactions and are responsive to neutrophil-derived chemokines ${ }^{297}$.
EAE was further confirmed in a separate study in mice and humans in vitro ${ }^{79}$, and the PC-specific transcription factor interferon regulatory factor 4 (IRF4) was shown to induce IL-10 expression ${ }^{80}$. Our laboratory has shown that mucosally derived IgA-producing PCs are a potent source of IL-10, and that they can express IL-10 within the inflamed brain and spinal cord during $\mathrm{EAE}^{81}$. Because the microbiota has been implicated in the production of IL- 10 by mucosal B cells ${ }^{82}$, this suggests that the dysbiosis which occurs during some chronic autoimmune diseases may impinge on the ability of $\mathrm{B}$ cell lineage cells to suppress inflammation. At the very least, the concept that 'regulatory $\mathrm{PCs}^{83}$ might exist must be carefully considered when one is interpreting BCDTs that differentially target PCs. Importantly, in humans, IL10-producing PCs can potentially be localized in the diseased tissue itself ${ }^{84}$.

\section{Systemic autoimmune diseases}

Our main BCDT tool is anti-CD20 antibodies - this therapy has been extensively tested in numerous autoimmune disease settings (FIG. 2). However anti-CD19 and anti-BAFF antibodies have also been tested in autoimmune disease indications. These agents, as well as new therapies at various stages of preclinical and clinical development, are described here in the context of systemic autoimmune diseases (TABLE 1).

BCDT in SLE. SLE has been a challenging disease to treat effectively, largely because it is heterogeneous, and this has become even more apparent in the bioinformatics $\mathrm{era}^{85}$. Indeed, there is only one approved biologic for SLE: belimumab, a fully humanized anti-BAFF monoclonal antibody $(\mathrm{mAb})$ that blocks the binding of BAFF to its cognate BAFF receptors on B cells. Unlike diseases, such as neuromyelitis optica (NMO), that are driven by autoantibodies to surface antigens, SLE is characterized by class-switched antibodies to intracellular antigens, particularly nuclear antigens ${ }^{86}$. The pathogenicity of these antibodies is because of their propensity to form immune complexes that cause tissue damage in multiple target organs; for example, lupus nephritis, which occurs in a subset of patients with SLE, affects the kidneys.

BAFF is a key B cell survival factor that, when overexpressed in mice, results in an expanded B cell compartment and relaxed negative selection within the $\mathrm{GC}^{87-89}$. Moreover, some patients with SLE exhibit sustained elevations in BAFF levels ${ }^{90}$. BAFF binds to three receptors, BAFF receptor (BAFFR; also known as TNFRSF13C), TACI (also known as TNFRSF13B) and BCMA (also known as TNFRSF170), all of which play important roles in promoting the survival of B cells. Different B cell subsets have a differential reliance on each receptor ${ }^{91,92}$.

As B cells are the effectors of this disease, BCDT has been examined in multiple human trials. Although belimumab was successful in phase III trials and is approved for the treatment of SLE ${ }^{93,94}$, many patients do not respond to belimumab, and we do not know whether this agent will alleviate lupus nephritis because individuals with renal disease were excluded from the trial ${ }^{95}$. In contrast, ianalumab, a novel BAFF-targeting antibody 
Multiple sclerosis

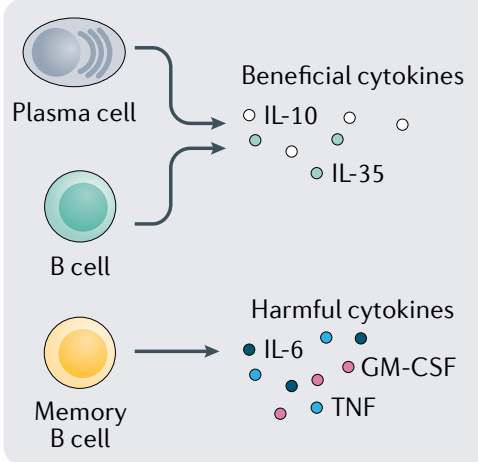

MOGSD

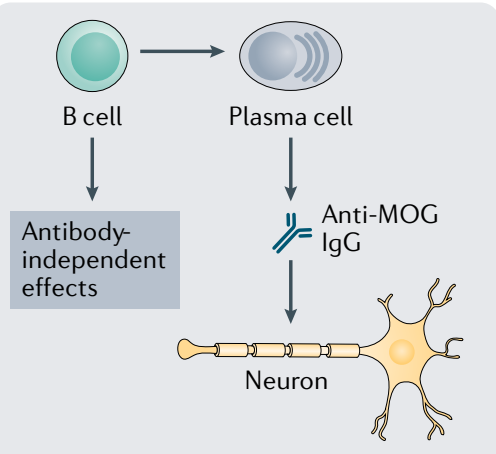

NMOSD

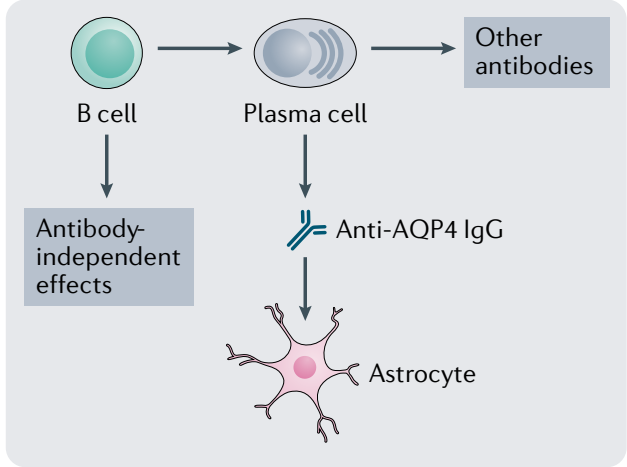

NMDAR encephalitis
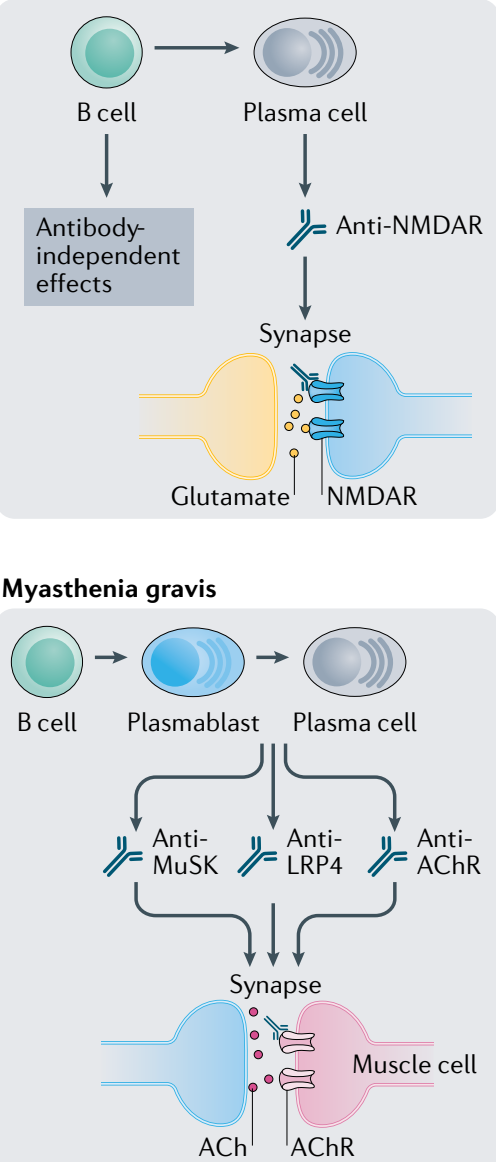

SLE

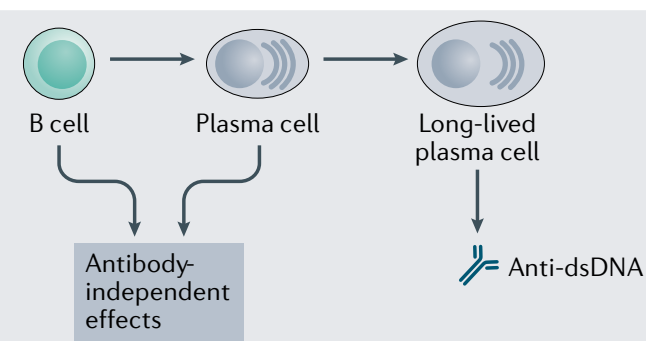

Rheumatoid arthritis

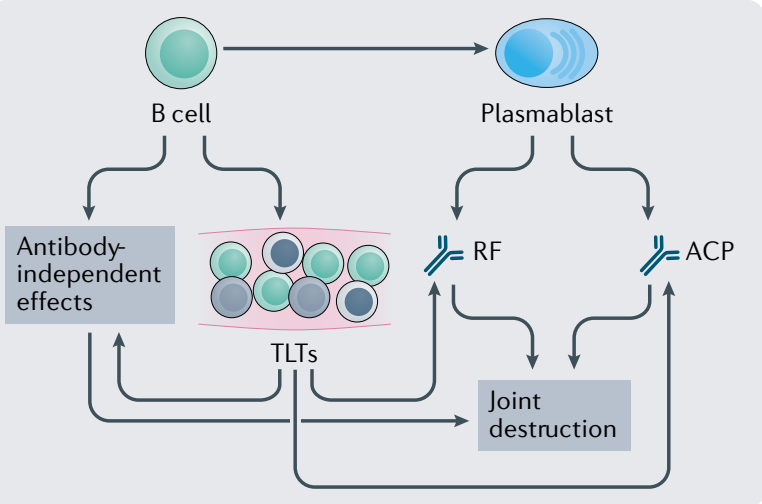

Myasthenia gravis

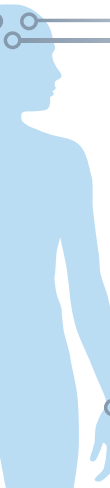

Glutamat

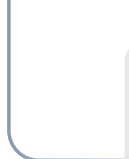

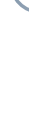

Fig. 2 | Roles of B cell lineage cells in autoimmune disorders. B cells and their effectors such as antibodies and cytokines differ in their contributions to pathobiology depending on the disease. Seven autoimmune disorders (multiple sclerosis, $\mathrm{N}$-methyl-D-aspartate receptor (NMDAR) encephalitis, myasthenia gravis, systemic lupus erythematosus (SLE), rheumatoid arthritis, myelin-oligodendrocyte glycoprotein (MOG) spectrum disorder (MOGSD) and neuromyelitis optica spectrum disorder (NMOSD)), their targets, and the implicated B cell subtype or pathogenic autoantibodies are shown. Based on the vast options for how B cells can influence pathobiology, patients must be carefully assessed to ensure that $B$ cell depletion therapy reduces pathogenic but not beneficial $B$ cell subsets. ACh, acetylcholine; AChR, nicotinic acetylcholine receptor; ACP, anti-citrullinated protein; AQP4, aquaporin 4; dsDNA, double-stranded DNA; GM-CSF, granulocyte-macrophage colony-stimulating factor; MuSK, muscle-specific tyrosine kinase; RF, rheumatoid factor; TLT, tertiary lymphoid tissue; TNF, tumour necrosis factor.

that prevents BAFF signalling by blocking BAFFR on $\mathrm{B}$ cells ${ }^{96}$, is worth considering, and this drug has had promising effects in Sjögren disease ${ }^{96}$.

In spite of early successes in open-label trials, an anti-CD20 antibody (rituximab) failed to meet its primary end points in two randomized controlled trials ${ }^{97,98}$, and worryingly, some patients experienced flares when B cells naturally reconstituted themselves after the drug was ceased ${ }^{99}$. The patients who experienced flares were those whose B cell compartments 
Table 1 | Selection of BCDTs being tested or currently approved for autoimmune diseases

\begin{tabular}{|c|c|c|c|c|}
\hline Drug name & $\begin{array}{l}\text { Target-based actions } \\
\text { (technology) }\end{array}$ & Therapeutic indications & Current status & $\begin{array}{l}\text { Notable trials } \\
\text { (ClinicalTrials. } \\
\text { gov identifier) }\end{array}$ \\
\hline \multicolumn{5}{|c|}{ mAbs targeting $C D 19$ or $C D 20$} \\
\hline \multirow[t]{2}{*}{ Rituximab } & \multirow[t]{2}{*}{ Chimeric anti-CD20 mAb } & Relapsing multiple sclerosis & Phase Il complete (used off-label) & NCT00097188 \\
\hline & & NMDAR encephalitis & Phase II complete & NCT03274375 \\
\hline \multirow[t]{4}{*}{ Ocrelizumab } & \multirow{4}{*}{$\begin{array}{l}\text { Humanized anti-CD20 } \\
\mathrm{mAb}\end{array}$} & \multirow{3}{*}{$\begin{array}{l}\text { Relapsing and progressive multiple } \\
\text { sclerosis }\end{array}$} & \multirow[t]{3}{*}{ Approved } & NCT03344094 \\
\hline & & & & NCT03523858 \\
\hline & & & & NCT04035005 \\
\hline & & Systemic lupus erythematosus & Phase III complete & NCT00626197 \\
\hline \multirow[t]{6}{*}{ Ofatumumab } & \multirow{6}{*}{$\begin{array}{l}\text { Fully humanized } \\
\text { anti-CD20 mAb }\end{array}$} & \multirow{3}{*}{ Relapsing multiple sclerosis } & \multirow{3}{*}{ Approved } & NCT03560739 \\
\hline & & & & NCT02792218 \\
\hline & & & & NCT02792231 \\
\hline & & Pemphigus vulgaris & Terminated for non-safety reasons & NCT01920477 \\
\hline & & \multirow[t]{2}{*}{ Rheumatoid arthritis } & \multirow{2}{*}{$\begin{array}{l}\text { Terminated to focus on subcutaneous } \\
\text { delivery }\end{array}$} & NCT00611455 \\
\hline & & & & NCT00603525 \\
\hline \multirow[t]{2}{*}{ Ublituximab } & \multirow{2}{*}{$\begin{array}{l}\text { Next-generation fully } \\
\text { humanized anti-CD20 mAb }\end{array}$} & \multirow[t]{2}{*}{ Relapsing multiple sclerosis } & \multirow[t]{2}{*}{ Phase III active } & NCT03277261 \\
\hline & & & & NCT03277248 \\
\hline Obinutuzumab & $\begin{array}{l}\text { Fully humanized } \\
\text { anti-CD20 mAb }\end{array}$ & Systemic lupus erythematosus & Phase Il complete & NCT02550652 \\
\hline \multirow{3}{*}{$\begin{array}{l}\text { Inebilizumab } \\
\text { (MEDI-551) }\end{array}$} & \multirow{3}{*}{$\begin{array}{l}\text { Humanized anti-CD19 } \\
\mathrm{mAb}\end{array}$} & NMOSD & Approved & NCT02200770 \\
\hline & & NMDAR encephalitis & Phase Il active & NCT04372615 \\
\hline & & Relapsing multiple sclerosis & Phase I complete & NCT01585766 \\
\hline $\begin{array}{l}\text { Obexelimab } \\
\text { (XMAB5871) }\end{array}$ & $\begin{array}{l}\text { Fully humanized anti-CD19 } \\
\text { antibody }\end{array}$ & Systemic lupus erythematosus & Phase II did not reach primary end points & NCT02725515 \\
\hline \multirow{3}{*}{$\begin{array}{l}\text { Belimumab } \\
\text { and rituximab } \\
\text { combination } \\
\text { therapy }\end{array}$} & \multirow{3}{*}{$\begin{array}{l}\text { Chimeric anti-CD20 and } \\
\text { fully humanized anti-BAFF } \\
\text { mAbs }\end{array}$} & Systemic lupus erythematosus & Phase III active & NCT03312907 \\
\hline & & Lupus nephritis & Phase II complete & NCT02260934 \\
\hline & & Idiopathic thrombocytopenic purpura & Prospective, without FDA-defined phase & NCT03154385 \\
\hline \multicolumn{5}{|l|}{ BAFF inhibitors } \\
\hline Belimumab & Anti-BAFF mAb & Systemic lupus erythematosus & Approved & NCT01729455 \\
\hline & & Vasculitis & Phase III complete & NCT01663623 \\
\hline & & Sjögren syndrome & Phase Il complete & NCT01160666 \\
\hline lanalumab & Anti-BAFF mAb & Systemic lupus erythematosus & Phase Il active & NCT03656562 \\
\hline & & Sjögren syndrome & Phase Il active & NCT02962895 \\
\hline & & Rheumatoid arthritis & Phase I active & NCT03574545 \\
\hline Telitacicept & TACl-Ig fusion protein & NMOSD & Phase III active & NCT03330418 \\
\hline & & Rheumatoid arthritis & Phase III active & NCT03016013 \\
\hline & & Myasthenia gravis & Phase Il active & NCT04302103 \\
\hline & & Multiple sclerosis & Interventional, without FDA-defined phase & NCT03744351 \\
\hline AMG 570 & Bispecific anti-BAFF & Systemic lupus erythematosus & Phase II active & NCT04058028 \\
\hline & peptibody, anti-ICOSL mAb & Rheumatoid arthritis & Phase I complete & NCT03156023 \\
\hline BTK inhibitors & & & & \\
\hline Tolebrutinib & Small molecule & Relapsing multiple sclerosis & Phase III active & NCT04410978 \\
\hline & & & & NCT04410991 \\
\hline & & Secondary progressive multiple sclerosis & Phase III active & NCT04411641 \\
\hline & & Primary progressive multiple sclerosis & Phase III active & NCT04458051 \\
\hline Evobrutinib & Small molecule & Relapsing multiple sclerosis & Phase II/III active & NCT02975349 \\
\hline & & & & NCT04338022 \\
\hline & & & & NCT04338061 \\
\hline CAR T cell ther & & & & \\
\hline $\begin{array}{l}\text { Anti-CD19 } \\
\text { CART cell }\end{array}$ & Anti-CD19 & Systemic lupus erythematosus & Status unknown & NCT03030976 \\
\hline Descartes-08 & Anti-BCMA & Myasthenia gravis & Phase $\mathrm{lb} / \mathrm{ll}$ a active & NCT04146051 \\
\hline & & Multiple myeloma & Phase $\mathrm{I} / \mathrm{Il}$ active & NCT03448978 \\
\hline DSG3-CAART & Anti-desmoglein 3 & Mucosal-dominant pemphigus vulgaris & Phase I active & NCT04422912 \\
\hline
\end{tabular}

CAR, chimeric antigen receptor; ICOSL, inducible T-cell costimulator ligand; mAb, monoclonal antibody; NMDAR, N-methyl-D-aspartate receptor; NMOSD, neuromyelitis optica spectrum disorder; $\mathrm{TACl}-\mathrm{lg}$, a recombinant fusion protein of the extracellular domain of $\mathrm{TACl}$ and a modified $\mathrm{Fc}$ portion of human immunoglobulin. 
were repopulated quickly and disproportionately with PBs, and these patients had high levels of antibodies to double-stranded DNA (anti-dsDNA) ${ }^{100}$. Indeed, a $\mathrm{PB}$ gene signature is associated with severe disease $\mathrm{e}^{101}$. One compelling hypothesis to explain these flares could be that BAFF expression, which is elevated after rituximab treatment, promotes B cell expansion on drug use cessation $^{102,103}$

Another mechanism for depleting B cells is to target the CD19 co-receptor using obexelimab, a humanized antibody that is also engineered to engage the Fc $\gamma$ receptor Fc $\gamma$ RIIb as a means of inhibiting BCR and/or TLR9 signalling to increase efficacy ${ }^{104}$. Unlike CD20, CD19 is expressed on bone marrow-resident pro- $\mathrm{B}$ cells and pre-B cells as well as some PBs and $\mathrm{PCs}^{105}$ (although the most mature PCs, the LLPCs, many of which reside in the gut, are $\mathrm{CD}^{19} 9^{-}\left(\mathrm{REF}^{106}\right)$ ). Thus, antibodies that target CD19 may have broader effects on the B cell compartment than anti-CD20 antibodies. Although this may be an advantage for antibody-mediated diseases, there may also be safety concerns that accompany the loss of precursor B cells and many subsets of antibody-secreting cells. In a phase II trial of obexelimab, investigators tapered patients off immunosuppressive steroids before randomly assigning them to treatment groups. Although patients receiving obexelimab sustained their level of disease inactivity despite steroid withdrawal in initial studies $^{95}$, phase II clinical trials, completed in 2018 , failed to meet their primary end points ${ }^{107}$.

Removing B cells by inhibiting Bruton tyrosine kinase (BTK) is also being investigated. BTK is expressed in B cells and myeloid cells, and its kinase activity is induced by both BCR and Fc receptor engagement. On the basis of preclinical animal models with BTK inhibitors, a reversible orally administered BTK inhibitor, GDC-0853, is currently being tested in a phase II trial in SLE $^{95}$. It is difficult to speculate on the safety and efficacy of GDC-0853 using the lessons learned from anti-CD20 antibodies because GDC- 0853 will affect both B cells and Fc receptor-expressing cells. Nevertheless, because of safety concerns around B cell depletion (susceptibility to infection, for example), the rapid reversibility of this drug is certainly appealing.

One possible way to improve on these results is to combine therapies. On the basis of the possibility that 'bad' (that is, proinflammatory) B cells emerge after rituximab treatment in response to elevated BAFF levels, three separate trials are examining anti-CD20 treatment followed by anti-BAFF therapy. One of those trials failed to show a difference between rituximab versus rituximab plus belimumab, whereas the other trial did show an improvement in dual-treated participants. The third trial (BEAT-Lupus) will hopefully clarify whether this is a viable treatment option for patients with SLE ${ }^{95}$.

Another possibility is to target two cytokines with one drug. Atacicept (a TACI-Ig; a recombinant fusion protein of the extracellular domain of TACI and a modified Fc portion of human immunoglobulin) neutralizes both BAFF and the related cytokine APRIL. Thus, treatment with atacicept could inhibit signals downstream of all three BAFF receptors. Unfortunately, the atacicept trial in SLE was halted due to safety concerns: atacicept-treated patients experienced serious infections and proteinuria actually increased ${ }^{108}$.

BCDT in RA. RA is a chronic autoimmune disease that is mainly characterized by joint inflammation and bone and cartilage damage. RA can also affect a wide variety of body systems, including the skin, eyes, lungs and heart. Like SLE, autoantibodies have been associated with RA, notably rheumatoid factor (RF; antibodies that recognize the $\mathrm{Fc}$ region of $\mathrm{IgG}$ ) and anti-citrullinated protein antibodies (ACPA; antibodies that recognize proteins that have been post-translationally modified through deamination of arginine residues). The presence of ACPA is more specific than the presence of RF for diagnosing RA. Patients with RA who are seropositive for autoantibodies typically experience more severe disease ${ }^{109}$. Because of the role of antibodies in RA, anti-CD20 agents have been tested, and the use of rituximab as a BCDT has shown great promise $\mathrm{i}^{47,110}$. Of note, in a phase II trial of rituximab, circulating antibody levels were not altered by treatment ${ }^{47,48}$, even though patients who were seropositive had a more robust benefit from treatment than those who were seronegative ${ }^{111}$.

By contrast, treatment with atacicept failed to reduce the severity of RA (no significant change in the American College of Rheumatology criteria for $20 \%$ reduction in disease severity), despite reducing levels of $\mathrm{RF}^{112,113}$. Therefore, it remains unclear why anti-CD20 works in RA but atacicept does not, although one of the atacicept trials tested patients in whom treatment with TNF antagonists had failed and may therefore have represented a more treatment-resistant patient group. One possibility is that B cells in the synovium may propagate TLT formation that can support local production of antibody-secreting B cells ${ }^{114,115}$. Since the abundance of B cells in the synovium positively correlates with joint damage progression ${ }^{116}, \mathrm{~B}$ cell-rich TLT could be a viable target for anti-CD20 therapy. Indeed, anti-CD20 therapy depletes synovial B cells to various degrees, and the depth of depletion correlates with clinical response ${ }^{117,118}$.

Changes in B cell-associated cytokine production may be another key part of the mechanism of action of BCDT in RA. Indeed, B cells from patients with RA produce less IL-10, and BCDT corrects this defect, perhaps because the cells that repopulate the periphery are biased towards IL-10 production ${ }^{119,120}$. B cells from patients with RA also produce proinflammatory cytokines, and PCs in the joint produce TNF, one of the key cytokines involved in $\mathrm{RA}^{121}$. Importantly, joint-resident $\mathrm{B}$ cells also make RANKL (also known as TNFSF11), which could actively promote bone destruction ${ }^{122}$. Thus, a 'reset' in cytokine production as a consequence of BCDT may result in clinical benefit for the patient.

Other indications for BCDT. Mouse studies that examine the effects of B cell deficiency on different disease states provide us with clues for how B cells affect virtually every tissue. For example, B cells promote insulin resistance ${ }^{123}$ and hypertension ${ }^{124,125}$. In insulin resistance, not all $\mathrm{B}$ cells are pathogenic: IgA-producing PCs can indeed limit obesity-induced insulin resistance ${ }^{126}$. The number 
Complement

Circulating proteins that form a cascading reaction that

'complements' antibodies and

phagocytic cells in clearing

pathogens. The complement

reaction is a highly

inflammatory process. of B cells within the myocardium increases in murine models of myocardial infarction, and $\mathrm{B}$ cell depletion in the context of myocardial injury is beneficial (reviewed elsewhere ${ }^{127}$ ). B cells have also been implicated in a number of vascular conditions, including aneurysm ${ }^{128}$ and atherosclerosis ${ }^{129}$. As in insulin resistance, $\mathrm{B}$ cells may exert beneficial and pathogenic effects in atherosclerosis; for example, BAFF overexpression accompanied by the expansion of some $B$ cell subsets seems to be protective $e^{130}$. These preclinical experiments provide an impetus to explore BCDT in metabolic, myocardial and vascular disorders.

In humans, other indications that benefit from BCDT include pemphigus vulgaris, a severe and rare autoimmune disease that results in blisters on the skin and mucosal membranes, in which rituximab has remarkable effects ${ }^{131}$. Other disease states that are driven by autoreactive B cells, such as Sjögren syndrome, respond variably to anti-CD20 therapy, and trials targeting the BAFF pathway using ianalumab and belimumab are ongoing ${ }^{132}$.

Lastly, although BCDT obviously has a beneficial effect in B cell-derived malignancies, the role of B cells in other cancers has also been extensively studied. Although beyond the scope of this Review, not surprisingly, B cells can have both protumorigenic and antitumorigenic effects in non-B cell cancers, and this likely depends on the intratumour context and the nature of the tumour antigen $(\mathrm{s})^{133}$.

\section{Neurological autoimmune diseases}

A number of neurological disorders are diagnosed by, or linked to, abnormal antibody levels in the cerebrospinal fluid $(\mathrm{CSF})^{134}$. Therefore it was reasoned that with enough time, the PB and/or PC reservoir of central nervous system (CNS)-directed autoantibody-producing $B$ cells would be eroded in patients treated with BCDT. In this section, we briefly discuss B cells and BCDT in MS. We also discuss the efficacy of BCDT in other neurological autoimmune disorders that are associated with autoantibody production (FIG. 2; TABLE 1).

B cells in MS. MS is a chronic demyelinating disease of the CNS with no cure or known cause. Genetic and environmental factors play roles. In MS, a complex interplay of neurodegenerative and immunological processes damages the myelin sheaths that surround neurons. There are three clinical variations of MS: relapsingremitting MS (RRMS), primary progressive MS (PPMS) and secondary progressive MS (SPMS). RRMS is typified by episodes of clinical relapses - during which immune cells infiltrate the CNS and form focal lesions that can be detected by MRI - followed by clinical improvement and remyelination of lesion areas. Progressive forms of the disease (PPMS and SPMS) are considered to be more neurodegenerative in nature and have lower levels of inflammation and immune activation ${ }^{135}$. Without treatment, most patients with RRMS convert to SPMS, and reductions in conversion rates are often measured in clinical trials as a parameter for success. Not surprisingly, the efficacy of therapeutics differs between MS subtypes.
Historically, MS has been thought of as a T cellmediated disease. This was fuelled by genetic observations (the MS risk is associated with the $H L A-D R B 1^{\star} 15: 01$ allele) ${ }^{136}$, histopathology studies (T cells are much more abundant than B cells in MS lesions ${ }^{84,137}$ and the key observation that adoptive transfer of activated myelinspecific $T$ cells into naive mice is sufficient to cause $\mathrm{EAE}^{138}$. However, in other species, such as the marmoset, B cells are necessary for disease ${ }^{139,140}$. Ironically, the importance of B cells in MS has been appreciated for many years. One of the earliest diagnostics for MS was the presence of IgG oligoclonal bands in the CSF, implying the presence of intrathecal antibody-producing cells $^{141,142}$. Evidence of B cell accumulation in CNS lesions ${ }^{143}$ and ectopic $\mathrm{B}$ cell follicles in the meninges of patients with SPMS (and, to a lesser extent, those with PPMS) ${ }^{137,144}$ further implicated B cells in the aetiopathology of the disease. Deposition of complexes containing antibodies and complement components in MS plaques also suggests that B cells are important in MS pathogenesis ${ }^{145,146}$, although in a separate study these complexes were not found to be a specific feature of lesions, nor a hallmark of MS in particular ${ }^{147}$. To date, no specific autoantibody has been demonstrated to be pathogenic and/or pathognomonic.

Studies have begun to characterize B cells in the blood of individuals with MS, and have examined the localization of B cells in the inflamed CNS. Specifically, NBCs in the peripheral blood of patients with MS have altered cytokine profiles: typically a decreased ability to produce IL-10, and increased production of IL-6, GM-CSF and $\mathrm{LTa}_{3}\left(\mathrm{REFS}^{60,75,148-150}\right)$. Interestingly, these aberrant cytokine profiles are normalized in B cells in the blood of patients with MS who have reconstituted their B cell compartment after $\mathrm{BCDT}^{60}$. Therefore, these studies suggest that the proinflammatory cytokine profiles of $\mathrm{B}$ cells in the blood may alter the disease in individuals with MS and can be modulated by BCDT ${ }^{134,151}$.

In terms of CNS-resident $B$ cells, patients with active disease can accumulate B cells in the CSF, including antigen-experienced $B$ cell subsets such as MBCs and $\mathrm{PCs}^{152}$. Sequencing of the immunglobulin heavy chain variable region repertoire to ascertain clonal relationships between peripheral B cells and CNS-derived B cells revealed clonal relationships between $\mathrm{B}$ cells in the $\mathrm{CNS}$ and $\mathrm{B}$ cells in the cervical lymph nodes. Moreover, by building lineage trees based on the relative amount of affinity maturation compared with a germ line sequence, it was determined that ancestral B cell clones are enriched in the cervical lymph nodes compared with the CNS. This elegant study suggested that, although antigen-experienced B cells are clearly present in the CNS, most B cell maturation and activation occurs in the periphery ${ }^{153}$.

$\mathrm{B}$ cell infiltration is not equally distributed throughout the CNS. CD20 $0^{+}$B cells tend to accumulate in perivascular spaces and within the subarachnoid space of the leptomeninges rather than in the tissue parenchyma $^{84}$. B cell-enriched TLTs within the subarachnoid space are particularly evident in patients with SPMS, and these B cell-rich and PC-rich structures are typically associated with grey matter pathology in 
layer I of the underlying cortex (subpial lesions) $)^{137,154,155}$. However, it is difficult to know whether TLT structures are impacted by BCDT as their small size makes them extremely difficult to capture by MRI.

From these findings taken together, B cells show significant alterations in accumulation, localization and activation in patients with RRMS versus healthy controls, and thus BCDT was posited as a treatment option.

BCDT in MS. Most MS treatments focus on depleting or altering the trafficking of peripheral immune cells. This is very effective for treating RRMS, in which waves of proinflammatory leukocytes from the periphery breach the blood-brain barrier and subsequently promote focal demyelinating lesions. Traditionally, clinical trials in patients with MS use clinical disability and/or radiological evidence of lesions (by MRI) as end points to measure success. Newer trials use a combination of clinical relapse rate, MRI-based evidence of lesions and progression of disability (which together form 'no evidence of disease activity', (NEDA-3)) as an end point that is measured 1, 2 or even 5 years after treatment initiation. Disease-modifying therapies, which abrogate specific immune processes involved in RRMS pathogenesis, are very good treatment options for patients with MS. These therapeutics include fingolimod ${ }^{156}$, ozanimod ${ }^{157}$ and natalizumab ${ }^{158}$, whose clinical efficacy may be because they reduce lymphocyte trafficking to the CNS. Three BCDTs that target CD20 have shown efficacy in MS: rituximab $^{159}$, ocrelizumab ${ }^{160,161}$ and ofatumumab ${ }^{162,163}$.

HERMES, a phase II placebo-controlled clinical trial of rituximab in patients with RRMS, was remarkably successful and beat expectations. A priori criteria for the HERMES trial included a $60 \%$ reduction in active gadolinium-enhancing lesions over a 24 -week period in response to rituximab (although this efficacy may well have occurred before 24 weeks) ${ }^{159}$. Treatment effectively depleted B cells in the peripheral blood after 4-8 weeks and in the CSF after 24 weeks ${ }^{46,164-166}$. Amazingly, patients who received rituximab treatment had a $91 \%$ reduction in lesion load and a clinical benefit after only 12 weeks of treatment. A persistent reduction in new lesion development was observed for up to 48 weeks. Importantly, IgG titres in the CSF were unchanged and oligoclonal bands persisted $^{46,165}$. The benefit also persisted after the B cells repopulated following cessation of treatment ${ }^{46,165}$. In a more recent multicentre study ${ }^{167}$, patients treated with rituximab had greater reductions in annual relapse rates than those treated with IFN $\beta$, a front-line therapy ${ }^{168}$ From these findings taken together, rituximab treatment considerably reduces clinical disease and reduces the lesions seen by brain imaging in people with MS, and these improvements correlate with a depletion of $B$ cells in the CSF and blood but not with changes in IgG in the CSF.

Other CD20-targeting BCDTs are also beneficial in people with MS. The concurrent clinical trials OPERA I and OPERA II tested the efficacy of the fully humanized $\mathrm{mAb}$ ocrelizumab in MS with similar results. Patients with RRMS who were treated with ocrelizumab had significant clinical benefit (46-47\% lower annualized relapse rate) and radiological improvement (94-95\% reduction in active lesions ${ }^{169}$. Ocrelizumab was also the first therapeutic that showed efficacy - albeit limited in patients with PPMS in the ORATORIO phase III clinical trial. In this trial, 12-week clinical disease progression was the primary end point: $32.9 \%$ of ocrelizumab-treated patients and $39.3 \%$ of IFN $\beta$-treated patients reached that end point ${ }^{160}$. Furthermore, MRI scans of the brain with T2-weighted images showed that ocrelizumab-treated patients had much smaller lesion volumes than patients who received IFN $\beta$. Although ocrelizumab was not as efficacious in PPMS as it was in RRMS, the ORATORIO clinical trial nevertheless met its primary end point and four of the five secondary end points. Since the progressive form of MS has very few treatment options, ocrelizumab has been approved by the FDA for this patient population and has begun to meet the significant unmet need. Notably, ocrelizumab seems to work better in a subset of younger patients (younger than 51 years) with PPMS who also have active inflammation ${ }^{170}$.

Attempts to improve these anti-CD20 therapeutics are ongoing. A subcutaneously delivered form of ofatumumab had similar results to other BCDTs in phase II trials (such as MIRROR and APLIOS, NCT03560739) ${ }^{162}$, and outperformed teriflunomide, a front-line therapy for MS, in a phase III trial ${ }^{163}$. One major advantage of subcutaneous delivery, compared with intravenous delivery (which is used for most BCDTs), is that it renders a drug easier for patients to self-administer. The phase III trials ASCLEPIOS I and ASCLEPIOS II (NCT02792218 and NCT02792231) are currently testing the efficacy of ofatumumab delivered via an autoinjector pen. Ublituximab is a next-generation anti-CD20 IgG1 mAb that binds an epitope on CD20 (including residues 168-171 and 158 and 159) that is distinct from the epitope bound by rituximab and ocrelizumab ${ }^{171}$ or the epitope bound by ofatumumab $^{172}$. Ublituximab has been glycoengineered to have a low fucose content in its Fc region, which should enhance its affinity for Fc $\gamma$ RIIIa receptors and maximize antibody-dependent cellular cytotoxicity (ADCC) toward B cells ${ }^{173,174}$. In phase II clinical trials, ublituximab also led to $\mathrm{B}$ cell depletion and a reduction in gadolinium-enhancing T1 lesions, T2 lesion volume and annualized relapse rate ${ }^{171}$. Ublituximab is currently being evaluated in phase III clinical trials (ULTIMATE 1 (NCT03277261) and ULTIMATE 2 (NCT03277248)). Advancements in anti-CD20 therapies are key as they may both increase efficacy and improve access for patients.

Due to the success of anti-CD20 therapies, other approaches for targeting B cells have been tested in the clinic. Targeting CD19 instead of CD20 affects a wider array of B cells, and includes PBs, which may significantly contribute to inflammation in the $\mathrm{CNS}^{175,176}$. In a phase I clinical trial, an anti-CD19 antibody (inebilizumab) showed a trend towards fewer gadoliniumenhancing lesions as well as a reduction in the number of new or newly enlarged T2-weighted lesions ${ }^{177}$. Evobrutinib, a BTK inhibitor, has also been tested in a phase II clinical trial. Evobrutinib reduced brain lesions as assessed by MRI, but did not alter the annualized relapse rate or disability progression ${ }^{178}$. However, the trial enrolled patients with an unusually high baseline level of clinical disability, and patients were older than 
those in similar trials. Thus, it is possible that some of the enrolled patients may have been transitioning from RRMS to SPMS, a form of MS that is fairly resistant to $\mathrm{BCDT}^{178}$. The evolutionRMS 1 and evolutionRMS 2 (NCT04338022 and NCT004338061) trials are currently examining the potential of evobrutinib in phase III clinical trials. Tolebrutinib (formerly SAR442168 or PRN-2246), another promising BTK inhibitor, is slated for phase III clinical trials in RRMS (GEMINI 1 (NCT04410978) and GEMINI 2 (NCT04410991)), SPMS (HERCULES (NCT04411641)) and PPMS (PERSEUS (NCT04458051)). Two features that distinguish BTK inhibitors from those targeting CD20 or other surface markers are that BTK inhibition may also target myeloid cells, which express BTK ${ }^{179}$, and that the increased bioavailability of BTK inhibitors within the CNS relative to antibody-based therapies may increase their efficacy.

Therapies that inhibit the BAFF/APRIL pathway have also been investigated in MS as an alternative strategy for 'starving' B cells, PBs and PCs of essential growth factors. The ATAMS phase II clinical trial was designed to do this by treating patients with MS with atacicept, the TACI-Ig fusion protein that binds and sequesters both BAFF and APRIL ${ }^{180}$. The hope was that atacicept would have a greater impact than CD20-directed therapies on MS because it would also impact PC survival. However, to the surprise of MS researchers, patients treated with atacicept experienced a dose-dependent increase in annualized relapse rates, and the atacicept treatment arm contained a lower proportion of relapse-free patients than the placebo arm. Therefore, due to the increased frequency of relapses, the clinical trial was prematurely discontinued ${ }^{180}$. In ATON, a phase II randomized clinical trial, patients who presented with optic neuritis as a clinically isolated syndrome were treated with atacicept and monitored over time ${ }^{181}$. Unfortunately, enrolment in ATON was halted because of the results in the ATAMS trial, but preliminary results in ATON showed less degeneration of retinal nerve fibre layer thickness with atacicept treatment. Despite this encouraging reduction in retinal nerve fibre layer damage, a greater proportion of patients in the atacicept group (6/17) had a second clinical attack and converted to clinically definite MS than in the placebo group (3/17). From the findings taken together, atacicept is not an appropriate treatment for MS; we speculate on reasons why this may be the case in the section entitled "Potential mechanism of action of BCDT".

Overall, some BCDTs are excellent treatment options for patients with MS (particularly RRMS, in which active inflammation is a prominent feature). However, the failure of another BCDT, atacicept, highlights our incomplete understanding of the nuances of B cells in MS. Data from these BCDT trials suggest that B cell subsets are heterogeneous in their capacity to regulate the immune response in MS. Moreover, the efficacy of anti-CD20 in MS is not related to a reduction in CSF antibody levels.

BCDT in anti-MOG spectrum disorders. The nearly universal presence of oligoclonal bands in the CSF of patients with MS spurred on efforts by many laboratories to measure autoantibodies to myelin-oligodendrocyte glycoprotein (MOG), the most abundant and accessible myelin antigen. Early studies indicated that some patients with MS were seropositive for anti-MOG $\mathrm{IgG}^{182,183}$. Moreover, immunization of mice with recombinant human MOG induces an EAE-like disease that is characterized by an anti-MOG IgG1 response that is necessary for clinical symptoms ${ }^{184-186}$. However, contrary to initial hypotheses, on closer examination, antibodies in the blood and CSF of patients with MS were not specific for the correctly folded form of MOG ${ }^{187,188}$. Soluble forms of the antigen are measured by standard enzyme-linked immunosorbent assay or western blot techniques ${ }^{189}$, but detection of antibodies to conformationally appropriate MOG, which is more biologically relevant, uses transfected human cells that express full-length MOG on the cell surface ${ }^{190}$. With these better diagnostic criteria, patients with MS had levels of anti-MOG that were very low, similar to those of healthy controls ${ }^{191-194}$, thus upending the concept that anti-MOG antibodies play a pathogenic role in MS. However, antibodies to other CNS antigens, particularly neuronal and glial targets, have been identified in patients with MS and may participate in the aetiopathology of the disease ${ }^{195-198}$. These antibodies are specific to diverse antigens, often to intracellular targets that reflect cell damage, and are possibly generated secondary to the initiating autoimmune attack $^{188,199-201}$

Anti-MOG antibodies can cause CNS autoimmune disorders other than MS, but these are currently not well stratified or classified ${ }^{194,202}$. These disorders have a range of phenotypes and are collectively referred to as MOG spectrum disorders (MOGSDs). Patients with MOGSDs largely present with an acute disseminated encephalomyelitis-like phenotype in younger patients and opticospinal phenotypes in older patients. Antibody-mediated demyelination (possibly via antiMOG antibodies) plays a role in these syndromes, and these disorders are now being teased apart from a similar set of diseases, NMO spectrum disorders (NMOSDs) ${ }^{203}$. MOGSDs provide an opportunity to assess the impact of BCDT in an antibody-mediated CNS disease setting. However, the heterogeneity of patients makes it difficult to conclusively determine the success or failure of a therapy ${ }^{204,205}$. Current treatment options for patients with an MOGSD include steroids or plasma exchange ${ }^{206}$. In early reports, rituximab had mixed clinical efficacy in MOGSD $^{205,207,208}$. More recently, a study in 121 patients with MOG antibody-associated disorder (MOGAD) showed that rituximab reduced relapse rates in patients with this disorder, but many patients continued to relapse despite B cell depletion ${ }^{209}$.

BCDT in other CNS diseases. MOGSD is not the only CNS disorder with a link to autoantibodies that may be altered by BCDT. NMOSD, a disease that primarily affects the spinal cord, optic nerves and brainstem, was previously considered a clinical variant of $\mathrm{MS}^{210}$. Examination of autoantibodies obtained from patients with NMOSD indicated that NMO-IgG, which are antibodies to aquaporin 4 (AQP4), are a unique feature not found in patients with $\mathrm{MS}^{211,212}$. In a report of 
patients with NMOSD at the national UK NMO clinic, $73 \%$ of patients were seropositive for $\mathrm{NMO}^{-\mathrm{IgG}^{213}}$. Of the NMO-IgG-seronegative patients, $42 \%$ were positive for anti-MOG IgG, further complicating the delineation between NMOSD and MOGSD. APQ4, which is targeted by NMO-IgG, is found on glial cells, and binding of NMO-IgG decreases aquaporin surface expression, resulting in increased permeability of the blood-brain barrier and complement activation, which promotes pathologies such as gliosis and axonal damage ${ }^{212,214}$. An anti-CD19 antibody, inebilizumab, was recently approved for NMO-IgG-seropositive patients with NMOSD following a promising phase II/III placebo-controlled clinical trial (N-Momentum (NCT02200770) $)^{215}$. AntiCD20 treatment also shows good clinical efficacy in NMOSD, although the therapeutic benefit does not correlate with a decrease in NMO-IgG levels in the blood $^{207,216}$. A TACI-Ig fusion protein, RC18, is also currently being examined in NMOSD in an interventional phase III clinical trial (NCT03330418). Therefore, the effect of BCDT in NMOSD is an active area of research, but observed reductions in disease are not entirely explained by a reduction in the autoantibody response. This observation suggests that NMOSD pathogenesis is not exclusively caused by NMO-IgG, or, alternatively, that measurements of these antibodies in the serum do not reflect ongoing pathogenesis in the $\mathrm{CNS}^{216}$.

Autoantibody-mediated encephalitis is a collection of neurological syndromes with numerous or unknown potential causes ${ }^{217}$. One of most common autoantibody-mediated encephalitis syndromes is characterized by a response to $N$-methyl-D-aspartate receptor (NMDAR). NMDAR is an ion channel and glutamate receptor that is critical for neurotransmitter signalling. Two primary causes of NMDAR encephalitis are currently understood. A small proportion of patients have anti-NMDAR encephalitis following infection with herpes simplex virus $1\left(\mathrm{REF}^{218}\right)$. More commonly, women with ovarian teratomas that express NMDARs can generate an NMDAR autoantibody response to the teratoma, and these antibodies eventually target NMDARs within the $\mathrm{CNS}^{219}$. This phenomenon was described in the popular Brain on Fire book and film, which were based on the experiences of a journalist at the New York Post who experienced anti-NMDAR autoimmunity ${ }^{217}$. Pathology from NMDAR autoantibodies is mediated by crosslinking NMDARs at the synapses on CNS neurons, leading to reduced levels of NMDAR, which likely alters memory, learning and other cognitive functions ${ }^{220}$. Despite the ovarian teratoma trigger, the anti-NMDAR immune response seems well compartmentalized to the CNS. Early reports have shown that rituximab leads to clinical improvement for anti-NMDAR encephalitis; however, it is not clear whether these improvements are because of changes in B cell numbers or because of changes in autoantibody levels ${ }^{221}$. Two BCDT trials are being conducted in anti-NMDAR encephalitis using rituximab (IANMDAR, a prospective phase II trial in paediatric patients with anti-NMDAR encephalitis (NCT03274375)) and inebilizumab (ExTINGUISH, a randomized phase IIb trial (NCT04372615)).
Myasthenia gravis (MG) is a neuromuscular disease that results in severe muscle weakness due to antibody-mediated blockade of nicotinic acetylcholine receptor (AChR) at neuromuscular junctions. This largely occurs due to an IgG1 or IgG3 autoantibody response to the $\mathrm{AChR}^{222}$. Targeting $\mathrm{AChR}$ leads to complement-mediated damage at the synapse and overt clinical symptoms. A subset of patients with MG test negative for antibodies to $\mathrm{AChR}$ and patients in those seronegative subgroups can be positive for other autoantibodies, such as anti-muscle-specific tyrosine kinase (anti-MuSK) IgG4 or anti-LRP4 IgG1 or IgG2. Standard treatment for MG includes the use of immunosuppressive steroids $^{223}$, but BCDT has also been investigated as a more targeted approach. Of note, patients with anti-MuSK antibodies fared better with rituximab therapy than patients with other autoantibodies such as anti-AChR ${ }^{224,225}$. Efficacy in patients with anti-MuSK antibodies correlated with a reduction in anti-MuSK IgG4 in the serum; of note, the anti-AChR antibodies were predominantly IgG1 and IgG3 (REF. ${ }^{225}$ ). Taken together, BCDT provides therapeutic benefit in some but not all patients with MG and the serotype is a key indicator for clinical success ${ }^{225}$.

Lastly, a constellation of rare CNS diseases driven by IgG4 antibodies are receiving increased interest. IgG4, which has low affinity for the complement component $\mathrm{Clq}$ and $\mathrm{Fc}$ receptors, is an unusual IgG because it readily undergoes Fab arm exchange with other IgG4 molecules, leading to bispecific IgG4 molecules. Such molecules cannot form large immune complexes, and hence they cause little or no inflammation ${ }^{226}$. Although IgG4 was initially considered as an anti-inflammatory immunoglobulin, IgG4 is implicated in several autoimmune diseases, most notably $\mathrm{MG}^{227}$. Additionally, IgG4 has been linked to neuropathies, encephalitis (IgG4 antibodies targeting leucine-rich glioma-inactivated protein 1 (LGI1)), and pemphigus (pemphigus foliaceus and pemphigus vulgaris). As mentioned, rituximab is selectively efficacious in patients with MG who have anti-MuSK IgG4 (REF. ${ }^{225}$ ).

Because of the rapid efficacy of BCDT in patients with anti-MuSK IgG4, it is possible that the cells that make these IgG4 antibodies (PBs) are not long lived; thus, BCDT prevents replenishment of the pathogenic IgG4 antibody-producing pool. Indeed, O'Connor and colleagues have shown that the precursors to these $\mathrm{PBs}$ are derived from antigen-experienced $\mathrm{CD} 27^{+} \mathrm{B}$ cells that are impacted by BCDT, and when incompletely depleted, these $\mathrm{CD} 27^{+} \mathrm{B}$ cells can drive disease flares ${ }^{228}$. Alternatively, the cells making anti-MuSK IgG4 may express the CD20 antigen and are thus susceptible to outright depletion. If this is true, these IgG4-mediated diseases may be particularly sensitive to BCDT. However, the scarcity and heterogeneity of IgG4-mediated autoimmune disorders means that designing good clinical trials is challenging.

In summary, clinical trials in CNS diseases in which $\mathrm{B}$ cells and/or autoantibodies participate highlight that BCDT cannot be used indiscriminately for therapy. Accordingly, the choice of BCDT requires careful examination of B cell subsets and their antibody-dependent and antibody-independent functions. 
Potential mechanism of action of BCDT. The successes of anti-CD20 treatment in autoimmune diseases such as RA and MS are some of the most encouraging examples of positive clinical outcomes for disease-modifying therapies in autoimmune diseases that have been traditionally difficult to treat. However, not all B cell-driven diseases respond to BCDT (SLE, for example, does not). The reason for such disparity is still unclear. Here, we discuss some working hypotheses for why BCDT may not always work and speculate on why it sometimes does work when we did not expect it to (FIG. 3).

Antibody design. On the basis of the success of BCDT in some indications, second-generation anti-CD20 mAbs have rapidly emerged. Different anti-CD20 mAbs evoke distinct cytotoxic mechanisms: complement-dependent cellular cytotoxicity (CDC), Fc $\gamma$ R-mediated depletion through cellular effector mechanisms including ADCC and antibody-dependent cellular phagocytosis, and directly inducing cell death ${ }^{229}$. Anti-CD20 mAbs can be divided into two types (type I and type II) on the basis of their ability to redistribute CD20 into plasma membrane lipid rafts, and their potency in assays measuring CDC, homotypic adhesion and programmed cell death induction $^{230}$. More recently, with use of cryo-electron microscopy it has been shown that type I mAbs can act as molecular 'seeds' to increase the local mAb concentration, which promotes $\mathrm{CDC}^{231}$. The first generation of genetically engineered chimeric anti-CD20 mAbs, such as rituximab and ocrelizumab, are type I mAbs. Rituximab comprises a murine variable region (Fab) and a human constant region $(\mathrm{Fc})$, whereas ocrelizumab is a humanized anti-CD20 IgG1. Ocrelizumab has superior ADCC activity in comparison with rituximab ${ }^{232,233}$. The main mechanism through which type I anti-CD20 $\mathrm{mAbs}$ deplete $\mathrm{B}$ cells is by redistribution of $\mathrm{CD} 20$ into lipid rafts: $\mathrm{mAb}$-driven $\mathrm{CD} 20$ clustering results in $\mathrm{CDC}$, although the process of cell death is independent of raft formation ${ }^{234}$. However, internalization of type I anti-CD20 mAbs from the surface via Fc $\gamma$ RIIb results

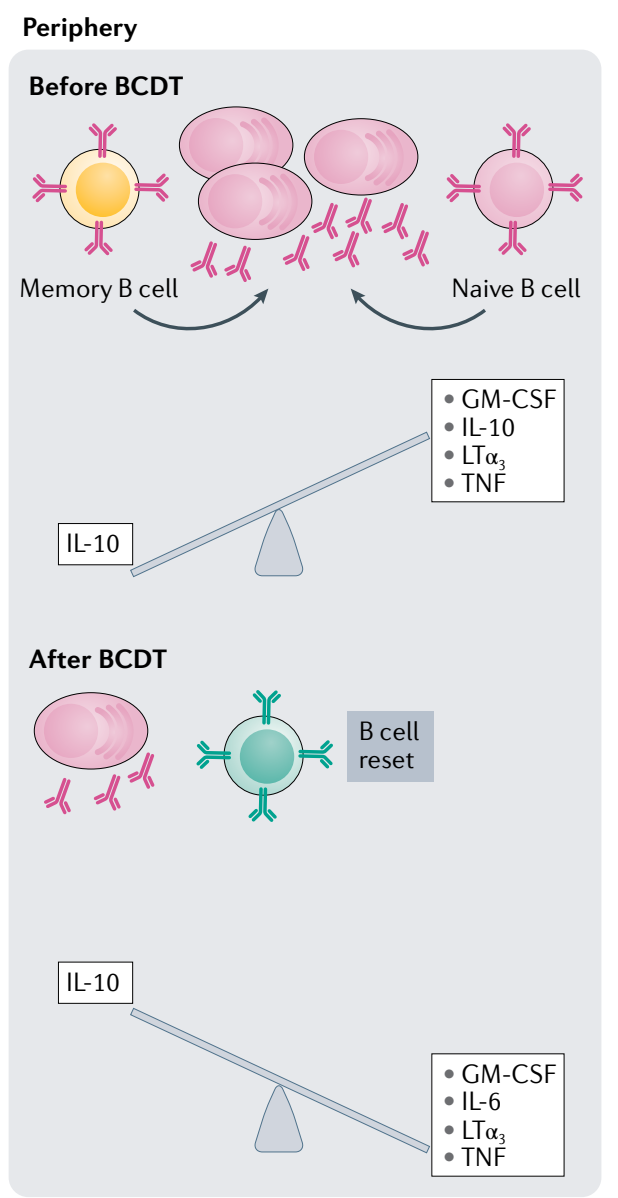

LLPC niches (BM, gut)

Before BCDT

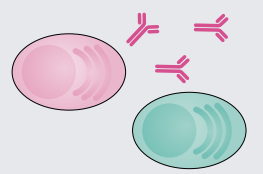

Plasma cells

After BCDT

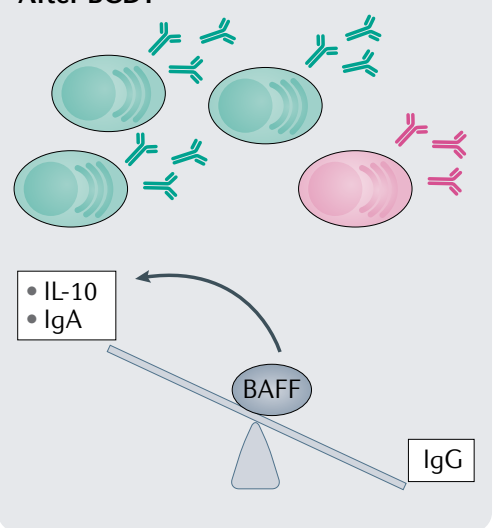

Target tissues

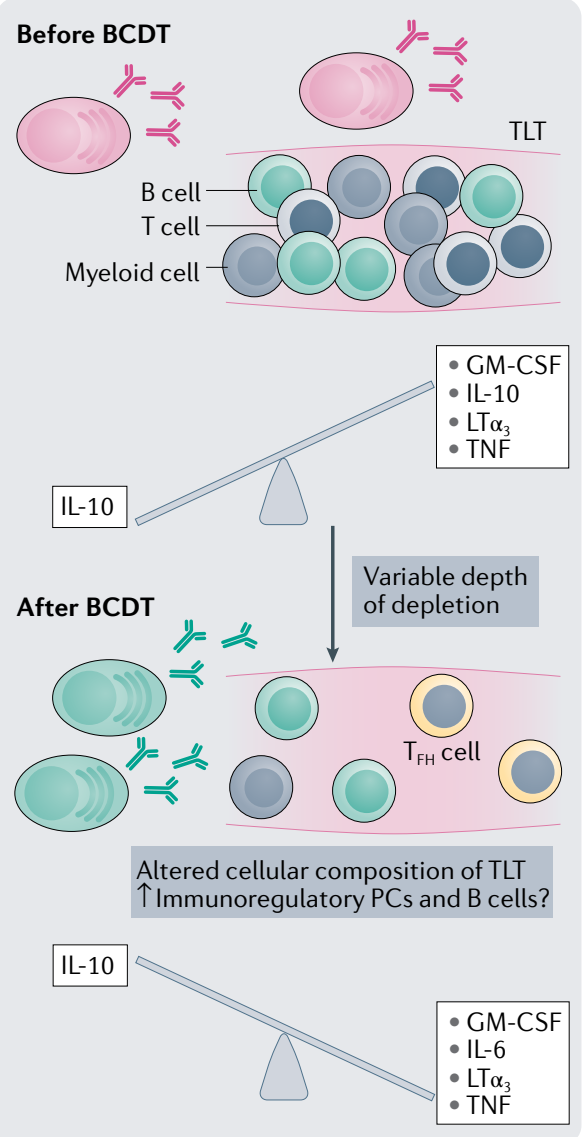

Fig. 3 | Effects of BCDT on B cell populations. Most of our knowledge of how $B$ cell populations change after $B$ cell depletion therapy (BCDT) is derived from treatment with anti-CD20 agents and is depicted here. We hypothesize that the efficacy of BCDT in some autoimmune diseases begins with a reset of the $B$ cell pool in the periphery. By elimination of $C D 20^{+}$ memory $B$ cells, some of which may be producing proinflammatory cytokines such as granulocyte-macrophage colony-stimulating factor (GM-CSF), the periphery is enriched with naive B cells and IL-10-producing regulatory B cells. Moreover, short-lived plasmablasts that are potentially autoreactive are not replenished by autoreactive memory B cells after
BCDT. Long-lived plasma cells (LLPCs), however, which are present in the bone marrow (BM) and gut, are not eliminated. Surges in BAFF levels that occur after BCDT may promote the accumulation of immunoregulatory LLPCs, which could have a beneficial effect in some diseases, such as multiple sclerosis. In target tissues, B cells in tertiary lymphoid tissues (TLTs) may not be replaced. Consequently, the ability for other pathogenic immune cells to take up residence in the inflamed tissue may be compromised, and other immunoregulatory cells, such as $T$ follicular helper cells $\left(\mathrm{T}_{\mathrm{FH}}\right.$ cells), may take up residence, resulting in reduced disease. $\mathrm{LTa} \alpha_{3}$, lymphotoxin- $\alpha_{3} ; P C$, plasma cell; TNF, tumour necrosis factor. 
Reticuloendothelial system A mixture of phagocytic cells that are responsible for the clearance of particles.

The binding of immunoglobulin to the Fc receptors of reticuloendothelial cells results in phagocytosis. in resistance to therapy and decreased clinical efficacy ${ }^{235}$. Type II mAbs, such as obinutuzumab, are fully humanized $\mathrm{mAbs}$. Compared with rituximab, this type II $\mathrm{mAb}$ binds to a different epitope, and does not induce efficient clustering of CD20 or antibody internalization, thus increasing efficacy and decreasing possible treatment resistance ${ }^{236}$. Hence these type II mAbs may have greater efficacy in diseases in which BCDT has shown only marginal efficacy.

Tissue and B cell lineage specificity. BCDT has a range of outcomes depending on the disease. One relatively straightforward reason for this variability is that pathogenic B cells in some scenarios are difficult to access (for example, because B cells localize into TLTs in the synovium or the leptomeninges). The depth of B cell depletion may therefore depend on the target tissue. For instance, the levels of synovial B cells were decreased but not fully eliminated in RA after BCDT ${ }^{117}$. Also, GC $B$ cells in Peyer patches and peritoneal B-1 cells resist rituximab treatment in human CD20 transgenic mice, as these antibodies need to access the vasculature to deliver the antibody-bound B cells to effector cells of the reticuloendothelial system ${ }^{44}$. In MS, B cell depletion is effective in the blood and $\mathrm{CSF}^{164,165}$, but variable in the $\mathrm{CNS}^{237,238}$. Inflammation in MS can be CNS compartmentalized into TLTs (for example, in the leptomeninges), so B cells may persist in these locations, particularly because survival factors such as BAFF are locally produced by astrocytes ${ }^{239}$. Furthermore, a substantial reservoir of T-bet ${ }^{+}$MBCs that express CD11c resides in the spleen and does not circulate. T-bet ${ }^{+} \mathrm{MBC}$ can be precursors to antibody-producing cells that could play a pathogenic role in autoimmune diseases such as SLE ${ }^{39}$. It is unclear whether anti-CD20 treatment effectively depletes these tissue-resident cells.

BCDT may also have variable outcomes in different autoimmune diseases if the pathogenic $B$ cell lineage does not express CD20 and turnover is slow. For example, CD20 is largely absent on subsets of LLPCs in healthy human bone marrow ${ }^{240}$ and gut ${ }^{106}$. For this reason, anti-CD20 therapy does not substantially deplete LLPCs. New approaches that target CD19, such as using an anti-CD19 mAb or a CD19-specific chimeric antigen receptor (CAR)-based T cell therapy, have been explored for some $\mathrm{B}$ cell malignancies ${ }^{241}$. However, a population of LLPCs that do not express CD19 nevertheless persists after infusion ${ }^{242}$. Thus, when anti-CD20 therapy has robust efficacy in diseases that are known to be mediated by autoantibodies, such as ANCA-associated vasculitis, NMO and pemphigus vulgaris, this efficacy may be due, at least in part, to a loss of short lived PBs or PCs that are not replaced because precursor B cells are also depleted.

On the other end of the efficiency spectrum, antiCD20 therapy has low efficacy in SLE, the canonical $\mathrm{B}$ cell-driven disease. We posit that this may be because pathogenic LLPCs that are CD20- and thus resistant to rituximab have a critical role in SLE. Not only does this potentially explain why anti-CD20 therapy failed in SLE, in which LLPCs are an important source of anti-DNA antibodies $^{243}$, it may also explain why, after BCDT, autoantibodies persist in $\mathrm{RA}^{244}$ and $\mathrm{NMO}^{245}$, oligoclonal bands remain in $\mathrm{MS}^{46}$ and protective antibodies elicited by previous vaccinations can still be found ${ }^{246}$.

Impact on cytokine-producing cells. The efficacy of BCDT in the absence of altered autoantibody levels suggests that antibody-independent B cell functions, such as cytokine production, could be important. Cytokines produced by B cells may alter the function of other immune cells such as T cells and myeloid cells. For example, in MS, B cells produce very high quantities of cytokines such as TNF, IL-6 and GM-CSF ${ }^{75,247}$. IL-6 produced by B cells has been clearly linked with the generation of a T helper 17 cell inflammatory immune response in EAE, and a similar observation has been made in humans: circulating B cells from patients with MS overproduce IL- 6 in vitro, and anti-CD20 treatment normalizes IL-6 production ${ }^{59}$. Indeed, in patients with MS, B cells that were reconstituted following BCDT had totally different cytokine profiles compared with B cells from untreated patients. Reconstituted B cells were characterized by limited proinflammatory cytokine production and higher production of anti-inflammatory IL-10 (REF. ${ }^{60}$ ). Thus, BCDT may produce a clean slate for peripheral B cells, providing a much-needed cytokine reset for the patient.

Antigen presentation and MBCs. In addition to producing antibodies and cytokines, B cells can internalize and process antigens, and then present them to $\mathrm{CD}^{+}$and $\mathrm{CD}^{+} \mathrm{T}$ cells via MHC class I and MHC class II, respectively. Interestingly, in EAE induced by full-length recombinant human MOG, the antigen presentation capacity of B cells was critical to disease induction, and passive transfer of pathogenic autoantibodies could only partially rescue disease severity if MHC class II was specifically deleted in the B cell compartment $^{248,249}$. Although B cells are considered to be less efficient antigen-presenting cells than dendritic cells, MBCs can play an important role in antigen presentation, particularly if $B$ cells present the same antigen as the responding $\mathrm{T}$ cell ${ }^{250}$.

B cells also mediate the proliferation of brain-homing autoreactive myelin-specific $\mathrm{CD} 4^{+} \mathrm{T}$ cells independently of any external $\mathrm{T}$ cell stimuli, and this function is lost after rituximab treatment ${ }^{251}$. These myelin-specific $\mathrm{CD}^{+}$ $\mathrm{T}$ cells increase in number predominantly in patients with MS who express the HLA-DR15 haplotype and decrease in number after anti-CD20 treatment ${ }^{251}$, providing further evidence that interrupting $\mathrm{B}$ cell-T cell interactions by BCDT may be relevant to MS aetiopathology. In summary, it is possible that BCDT is efficacious in part because it abrogates proinflammatory antigen presentation by B cells.

Other hypotheses on mechanism. The effects on non$B$ cells may explain the success of anti-CD20 therapy in MS. The existence of a rare population of $\mathrm{CD}^{+} \mathrm{T}$ cells that concomitantly express CD20 was first described in 1993 by flow cytometry ${ }^{252}$. CD20 ${ }^{+} \mathrm{T}$ cells have also been described in patients with $\mathrm{RA}^{253}$ as well as $\mathrm{MS}^{254}$. Some patients with MS have an increased number of peripheral 
$\mathrm{CD}^{+} \mathrm{CD} 20^{\text {low }} \mathrm{T}$ cells, which can be efficiently depleted by rituximab ${ }^{255}$. Subsequently, with use of myelin-MHC class I tetramers to identify myelin-specific $\mathrm{CD}^{+} \mathrm{T}$ cells in peripheral blood, the number of myelin-specific $\mathrm{CD} 20^{+} \mathrm{CD} 8^{+} \mathrm{T}$ cells was found to be increased in patients with MS, and the number of these cells was reduced after anti-CD20 treatment ${ }^{256}$. In addition, the presence of CSF-resident highly proliferative IFN $\gamma$-producing $\mathrm{CD}^{+}$and $\mathrm{CD}^{+} \mathrm{T}$ cells that express $\mathrm{CD} 20$ positively correlates with disease severity in $\mathrm{MS}^{254}$. Thus, anti-CD20 therapy may be effective partially because it removes $\mathrm{CD} 20^{+} \mathrm{T}$ cells.

In addition to this potential off-target-cell effect, removing B lymphocytes, an entire branch of the immune system, will change the availability of growth and survival factors that were previously consumed by these cells. Following anti-CD20 treatment in patients with MG, the relative proportion of PCs to B cells is increased, and $\operatorname{IgA}^{+} \mathrm{MBCs}$ outnumber other $\mathrm{MBCs}^{257}$. It is unclear why this happens, but it is important to remember that BAFF levels increase after rituximab treatment ${ }^{102,103}$. This elevation of BAFF may have different effects in different disease settings. In some patients with MS, BAFF levels are elevated in both the serum and the $\operatorname{CSF}^{258,259}$. Moreover, Steri et al. showed that a variant BAFF (also known as TNFSF13B) allele that favours overproduction of BAFF has been associated with $\mathrm{MS}^{260}$. This observation suggests that BAFF may be deleterious in MS. However, others have found that high blood BAFF levels correlate with a more stable disease course of $\mathrm{MS}^{261}$, and, as mentioned, BAFF inhibition with atacicept worsened MS disease ${ }^{180}$. The consequences of high BAFF levels in MS are unclear because of these contradictory observations. We have found that high BAFF levels strongly protect against EAE. In our study, mice that overexpressed BAFF had an abundance of IgA-producing PCs in the gut. These PCs also produce IL-10, and, when transferred into mice that lack IL-10, can confer protection against $\mathrm{EAE}^{81}$. BAFF and the related cytokine APRIL are key survival cytokines that sustain LLPCs ${ }^{262}$. APRIL can also promote class switching to $\operatorname{Ig} \mathrm{A}^{18,19}$. Thus, one potential mechanism for the efficacy of anti-CD20 therapy in MS is that BAFF levels are increased after treatment and consequently promote the survival of immunoregulatory PCs, particularly gut-derived IgA ${ }^{+}$PCs. Indeed, patients with RA who were treated with rituximab still have of $\operatorname{Ig} \mathrm{A}^{+}$ PCs in the lamina propria in gut biopsy samples ${ }^{263}$. This may also explain why inhibition of BAFF by atacicept had a negative outcome for patients with $\mathrm{MS}^{180}$.

This hypothesis may seem at odds with the findings of Steri et al. ${ }^{260}$. However, the study by Steri et al. did not examine whether patients with the variant allele had elevated levels of BAFF trimer or of higher-order structures of the cytokine. This is of critical importance because only highly oligomerized forms of BAFF (60-mer), or APRIL bound to heparin sulfate proteoglycan, stimulate $\mathrm{TACI}^{91,92}$. Thus, in contrast to the situation in SLE, in which high BAFF levels after rituximab treatment may be counterproductive ${ }^{102,103}$, increased BAFF levels capable of triggering TACI may be beneficial in MS.

\section{New therapeutic directions}

On the basis of what we have learned about B cells in the past 10 years, we might now be able to design therapies that provide superior specificity and sensitivity to thwart inflammatory B cells and foster the function and accumulation of immunoregulatory B cells (FIG. 4). In this section, we provide a few perspectives on what this could look like in the context of the findings discussed herein. One therapy type that has not been discussed, as it is beyond the scope of this Review, is drugs that target the CD40 pathway ${ }^{264,265}$. Although the first anti-CD40L drug (ruplizumab; BG9588) was not viable because it caused thrombotic side effects ${ }^{266}$, new and safer variants are being tested. Given the importance of CD40-dependent $\mathrm{T}$ cell-B cell interactions in the GC as provided by $\mathrm{T}_{\mathrm{FH}}$ cells, we optimistically await the results of testing new forms of anti-CD40 or anti-CD40L therapies in autoimmune disease settings ${ }^{267,268}$.

Targeting T-bet ${ }^{+} \boldsymbol{B}$ cells. Class-switched antibodies can be derived from T-bet ${ }^{+} \mathrm{B}$ cells. In patients with SLE, these unusual cells are poised to make autoantibodies, dominate the blood of patients with active disease, and may be derived from an extrafollicular response rather than from the $\mathrm{GC}^{38}$. Recently, Reizis and colleagues showed that PBs that emerge from extrafollicular responses and make anti-dsDNA antibodies rely on type I interferon produced by plasmacytoid dendritic cells ${ }^{269}$. Targeting these T-bet ${ }^{+} \mathrm{DN} 2$ cells by blocking IFN $\gamma$ or type I interferon is an appealing potential way to treat SLE given the importance of these cells in the disease. Indeed, anifrolumab, which blocks the interaction between the interferon receptor (IFNAR) and its type I interferon ligands, has shown modest promise in a phase III trial in SLE ${ }^{270}$.

Harnessing the regulatory potential of PCs. IL-10 is a direct target of the transcription factor IRF4 in PCs ${ }^{80}$. The inhibitory molecules PDL1, PDL2 and LAG3 are likewise expressed by PCs, and PCs are primed to make IL-10 as they have an open chromatin configuration at the $I L 10$ locus ${ }^{271}$. We have also shown that IgA-producing PCs can produce IL-10, and that the gut is a rich source of IL-10-producing PCs that can regulate neuroinflammation ${ }^{81}$. IgA-producing PCs in the gut can be extremely long-lived (measured in decades), and most LLPCs are negative for both CD19 and CD20 $\left(\mathrm{REF}^{81}{ }^{81}\right.$. It is unknown whether the lifespan potential of a PC correlates with its suppressive function. Nevertheless, if we can learn what factors enhance the accumulation of these cells - possibly BAFF or, in the context of the gut, particular microorganisms which we know are important for dictating IgA PC numbers ${ }^{272}$ - then this becomes a potential therapeutic approach for treating some autoimmune diseases.

Reconsidering MBCs. As illuminated by single-cell sequencing, the BCRs that are recruited into an immune response are not always the ones that we might expect. For example, Tan et al. identified a startlingly common insertion between the $\mathrm{V}$ and $\mathrm{DJ}$ fragments of the BCR that encodes the 98 amino acid collagen-binding domain of leukocyte-associated immunoglobulin-like 
Target non-circulating memory B cells

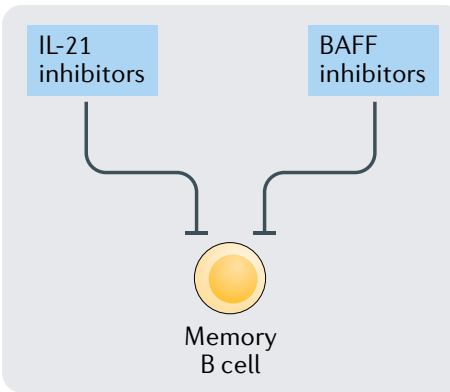

Decrease pathogenic cells in TLT

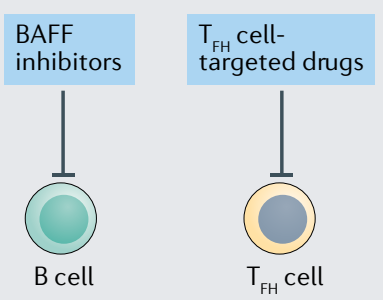

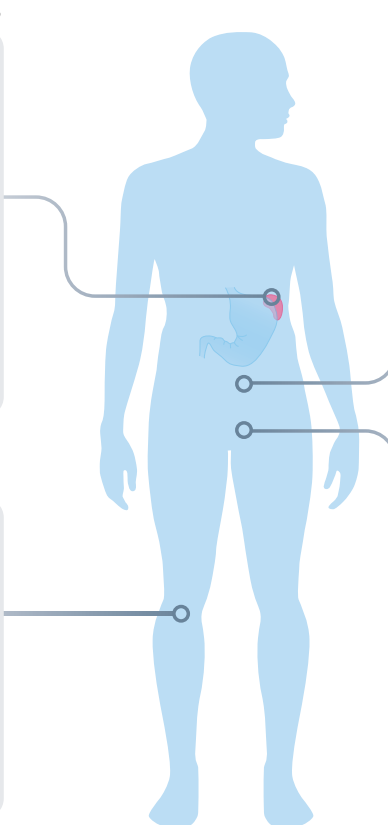

BAFF oligomer mimics Microbiota following anti-CD20 modulators depletion (MS only)
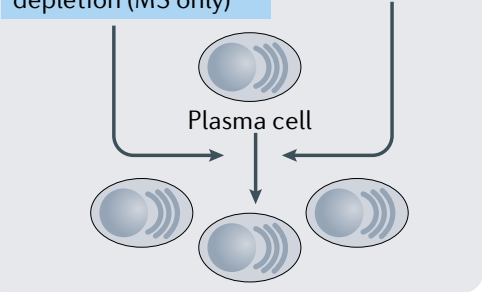

nhibit B cells in GC CD40 pathway inhibitors
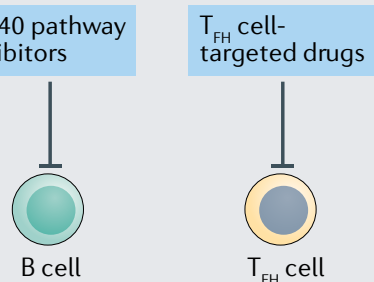

Fig. 4 | Future approaches using B cell-targeted therapies in autoimmune disease. The next generation of B celltargeted therapies, rather than B cell depletion therapies, will need to target specific proinflammatory and anti-inflammatory $B$ cell functions. BAFF homotrimers versus higher-order aggregates (60-mers) of BAFF or APRIL impact different B cell subsets differently. Inhibiting BAFF homotrimers could have a beneficial effect because it may remove T-bet ${ }^{+} \mathrm{B}$ cells and/or $\mathrm{B}$ cells that participate in the extrafollicular response. Because a subtype of T-bet ${ }^{+}$B cells (double-negative 2 (DN2) cells, which are considered to be non-circulating memory B cells) gives rise to antibody-producing plasmablasts and plasma cells in an IL-21-dependent manner, IL-21 blockade may ameliorate disease by inhibiting these non-circulating memory B cells. However, supplementation with BAFF 60-mers or APRIL may promote the accumulation of lgA ${ }^{+}$immunoregulatory plasma cells, which could be beneficial in multiple sclerosis (MS). Likewise, the levels of immunoregulatory plasma cells may be increased by manipulating the microbiota. The germinal centre (GC) itself is the source of somatically hypermutated B cells that play an important role in diseases such as systemic lupus erythematosus. Interrupting the entanglement between $B$ cells and $T$ follicular helper cells $T\left(T_{F H}\right.$ cells) by blocking CD40 (or other candidates such as inducible T cell costimulator (ICOS)) could provide a means for staving off this source of potentially bad B cells. In tertiary lymphoid tissues (TLTs), removal of B cells may change the cellular environment of TLT, reducing its ability to foster autoimmune reactions.

receptor 1 (LAIR1). The BCRs that contain LAIR1 can undergo somatic hypermutation, consequently losing their capacity to bind collagen but gaining the ability to bind to Plasmodium falciparum-infected erythrocytes $^{273}$, thus repurposing previously self-reactive B cells. Moreover, Murugan et al. showed that the initial B cell response to $P$. falciparum in humans who had never been exposed to the parasite was driven by $\mathrm{B}$ cell clones that had already undergone somatic hypermutation, demonstrating that MBCs can be recruited into de novo immune responses to completely different antigens ${ }^{274}$.

This makes good evolutionary sense: setting up a GC is an energetically expensive process that requires chemotaxis, antigen trapping and a substantial remodelling of stromal cell networks ${ }^{275}$. In addition to its role as a platform for affinity maturation of NBCs, why not use this environment to repurpose and 'redeem ${ }^{276}$ self-reactive $\mathrm{B}$ cells to participate in immune responses? While this is an exciting frontier in the evolution of our understanding of B cells, undoubtedly there are collateral consequences for the host when dealing with a live-or-die infection. Therefore, we must determine whether such repurposed B cell subsets can mediate damage to host tissues and, if they do, whether they are targeted by current therapeutics. Our intense research into the dynamics of the human B cell response to the SARS-CoV-2 pathogen will undoubtedly yield further surprises.

\section{Conclusions}

The field of BCDT began with a rather crude instrument (antibodies that deplete all $\mathrm{CD} 20^{+} \mathrm{B}$ cells). The clinical experiments performed with anti-CD20 therapy, however, have been surprising and revealing, spurring on research into how B cells impact disease. Our rudimentary idea that PCs and antibodies are 'bad' has matured considerably into a more nuanced view of $\mathrm{B}$ cells in health and disease. Moving forward, it will be important to not merely ascribe increasingly specific subset designations on the basis of emerging RNA sequencing data in the absence of a holistic view of the environment in which B cells differentiate and exist. For example, the microbiome is a key environmental factor that influences $B$ cell phenotype ${ }^{63}$. Taking cues from our co-evolution with pathogens, new perspectives on the roles of B cells in autoimmune disease will undoubtedly emerge. These perspectives, combined with advances in antibody technologies, should increase the efficacy and specificity of BCDTs in autoimmune diseases.

Published online 15 December 2020 
1. van Krieken, J. H. \& te Velde, J. Normal histology of the human spleen. Am. J. Surg. Pathol. 12, 777-785 (1988).

2. Phan, T. G., Gray, E. E. \& Cyster, J. G. The microanatomy of B cell activation. Curr. Opin. Immunol. 21, 258-265 (2009).

3. Lewis, S. M., Williams, A. \& Eisenbarth, S. C. Structure and function of the immune system in the spleen. Sci. Immunol. 4, eaau6085 (2019).

4. Kwak, K., Akkaya, M. \& Pierce, S. K. B cell signaling in context. Nat. Immunol. 20, 963-969 (2019).

5. Mesin, L., Ersching, J. \& Victora, G. D. Germinal center B cell dynamics. Immunity 45, 471-482 (2016).

6. Weisel, F., Shlomchik, M. \& Memory, B. Cells of mice and humans. Annu. Rev. Immunol. 35, 255-284 (2017).

7. Maloney, D. G. et al. Phase I clinical trial using escalating single-dose infusion of chimeric anti-CD20 monoclonal antibody (IDEC-C2B8) in patients with recurrent B-cell lymphoma. Blood 84, 2457-2466 (1994).

8. van Vollenhoven, R. F., Fleischmann, R. M., Furst, D. E., Lacey, S. \& Lehane, P. B. Longterm Safety of rituximab: final report of the rheumatoid arthritis global clinical trial program over 11 years. J. Rheumatol. 42, 1761-1766 (2015)

9. Browning, J. L. B cells move to centre stage: novel opportunities for autoimmune disease treatment. Nat. Rev. Drug Discov. 5, 564-576 (2006).

10. Vinuesa, C. G., Linterman, M. A., Yu, D. \& MacLennan, I. C. Follicular helper T cells. Annu. Rev. Immunol. 34, 335-368 (2016)

11. Liu, D. et al. T-B-cell entanglement and ICOSL-driven feed-forward regulation of germinal centre reaction. Nature 517, 214-218 (2015)

12. Casamayor-Palleja, M., Khan, M. \& MacLennan, I. C. A subset of $\mathrm{CD}^{+}$memory $\mathrm{T}$ cells contains preformed CD40 ligand that is rapidly but transiently expressed on their surface after activation through the T cell receptor complex. J. Exp. Med. 181, 1293-1301 (1995).

13. MacLennan, I. C. et al. Extrafollicular antibody responses. Immunol. Rev. 194, 8-18 (2003).

14. Kelly, L. M., Pereira, J. P., Yi, T., Xu, Y. \& Cyster, J. G. EBI2 guides serial movements of activated $B$ cells and ligand activity is detectable in lymphoid and nonlymphoid tissues. J. Immunol. 187, 3026-3032 (2011).

15. Gatto, D., Paus, D., Basten, A., Mackay, C. R. $\delta$ Brink, R. Guidance of $B$ cells by the orphan $G$ protein-coupled receptor EBI2 shapes humoral immune responses. Immunity 31, 259-269 (2009).

16. Lee, S. K. et al. B cell priming for extrafollicular antibody responses requires $\mathrm{Bcl}-6$ expression by T cells. J. Exp. Med. 208, 1377-1388 (2011).

17. Di Niro, R. et al. Salmonella infection drives promiscuous B cell activation followed by extrafollicula affinity maturation. Immunity 43, 120-131 (2015).

18. Xu, W. et al. Epithelial cells trigger frontline immunoglobulin class switching through a pathway regulated by the inhibitor SLPI. Nat. Immunol. 8 294-303 (2007)

19. He, B. et al. The transmembrane activator TACl triggers immunoglobulin class switching by activating B cells through the adaptor MyD88. Nat. Immunol. 11, 836-845 (2010).

20. Kim, H. J., Krenn, V., Steinhauser, G. \& Berek, C. Plasma cell development in synovial germinal centers in patients with rheumatoid and reactive arthritis. J. Immunol. 162, 3053-3062 (1999)

21. Scheel, T., Gursche, A., Zacher, J., Haupl, T. \& Berek, C. $V$-region gene analysis of locally defined synovial $B$ and plasma cells reveals selected $B$ cell expansion and accumulation of plasma cell clones in rheumatoid arthritis. Arthritis Rheum. 63, 63-72 (2011).

22. Schroder, A. E., Greiner, A., Seyfert, C. \& Berek, C. Differentiation of B cells in the nonlymphoid tissue of the synovial membrane of patients with rheumatoid arthritis. Proc. Natl Acad. Sci. USA 93, 221-225 (1996).

23. Stott, D. I., Hiepe, F., Hummel, M., Steinhauser, G. \& Berek, C. Antigen-driven clonal proliferation of B cells within the target tissue of an autoimmune disease. The salivary glands of patients with Sjogren's syndrome. J. Clin. Invest. 102, 938-946 (1998).

24. Shaffer, A. L. et al. Blimp-1 orchestrates plasma cell differentiation by extinguishing the mature $\mathrm{B}$ cell gene expression program. Immunity 17, 51-62 (2002).

25. Jacobson, B. A. et al. Anatomy of autoantibody production: dominant localization of antibody-producing cells to T cell zones in Fas-deficient mice. Immunity 3, 509-519 (1995).
26. William, J., Euler, C., Christensen, S. \& Shlomchik, M. J. Evolution of autoantibody responses via somatic hypermutation outside of germinal centers. Science 297, 2066-2070 (2002).

27. Groom, J. R. et al. BAFF and MyD88 signals promote a lupuslike disease independent of $\mathrm{T}$ cells. J. Exp. Med. 204, 1959-1971 (2007).

28. Giltiay, N. V. et al. Overexpression of TLR7 promotes cell-intrinsic expansion and autoantibody production by transitional T1 B cells. J. Exp. Med. 210 , 2773-2789 (2013).

29. Roco, J. A. et al. Class-switch recombination occurs infrequently in germinal centers. Immunity $\mathbf{5 1}$, 337-350.e7 (2019).

30. Warsame, A. et al. Monocytoid B cells: an enigmatic $B$ cell subset showing evidence of extrafollicular immunoglobulin gene somatic hypermutation. Scand. J. Immunol. 75, 500-509 (2012).

31. Jenks, S. A., Cashman, K. S., Woodruff, M. C. Lee, F. E. \& Sanz, I. Extrafollicular responses in humans and SLE. Immunol. Rev. 288, 136-148 (2019).

32. Myles, A., Sanz, I. \& Cancro, M. P. T-bet ${ }^{+}$B cells: common denominator in protective and autoreactive antibody responses? Curr. Opin. Immunol. 57, 40-45 (2019).

33. Brown, C. C. et al. Transcriptional basis of mouse and human dendritic cell heterogeneity. Cell 179 , 846-863 e824 (2019)

34. Wei, C. et al. A new population of cells lacking expression of $\mathrm{CD} 27$ represents a notable component of the B cell memory compartment in systemic lupus erythematosus. J. Immunol. 178, 6624-6633 (2007).

35. Zumaquero, E. et al. IFNgamma induces epigenetic programming of human T-bet ${ }^{\text {hi }} \mathrm{B}$ cells and promotes TLR7/8 and IL-21 induced differentiation. eLife $\mathbf{8}$, e41641 (2019).

36. Tipton, C. M. et al. Diversity, cellular origin and autoreactivity of antibody-secreting cell population expansions in acute systemic lupus erythematosus. Nat. Immunol. 16, 755-765 (2015).

37. Wang, S. et al. IL-21 drives expansion and plasma cell differentiation of autoreactive CD $11 \mathrm{C}^{\text {hiT-bet }}{ }^{+} \mathrm{B}$ cells in SLE. Nat. Commun. 9, 1758 (2018)

38. Jenks, S. A. et al. Distinct effector B cells induced by unregulated toll-like receptor 7 contribute to pathogenic responses in systemic lupus erythematosus. Immunity 49, 725-739.e6 (2018)

39. Johnson, J. L. et al. The transcription factor T-bet resolves memory B cell subsets with distinct tissue distributions and antibody specificities in mice and humans. Immunity 52, 742-855.e6 (2020).

40. Hao, Y., O’Neill, P., Naradikian, M. S., Scholz, J. L. \& Cancro, M. P. A B-cell subset uniquely responsive to innate stimuli accumulates in aged mice. Blood 118 1294-1304 (2011).

41. Rubtsov, A. V. et al. Toll-like receptor 7 (TLR7)-driven accumulation of a novel CD $11 \mathrm{C}^{+} \mathrm{B}$-cell population is important for the development of autoimmunity. Blood 118, 1305-1315 (2011).

42. Claes, N. et al. Age-associated B cells with proinflammatory characteristics are expanded in a proportion of multiple sclerosis patients. J. Immunol. 197, 4576-4583 (2016)

43. Ramskold, D. et al. B cell alterations during BAFF inhibition with belimumab in SLE. EBioMedicine $\mathbf{4 0}$ 517-527 (2019).

44. Gong, Q. et al. Importance of cellular microenvironment and circulatory dynamics in B cell immunotherapy. J. Immunol. 174, 817-826 (2005).

45. Looney, R. J. et al. B cell depletion as a novel treatment for systemic lupus erythematosus: a phase I/ll dose-escalation trial of rituximab. Arthritis Rheum. 50, 2580-2589 (2004)

46. Piccio, L. et al. Changes in B- and T-lymphocyte and chemokine levels with rituximab treatment in multiple sclerosis. Arch. Neurol. 67, 707-714 (2010).

47. Edwards, J. C. et al. Efficacy of B-cell-targeted therapy with rituximab in patients with rheumatoid arthritis. N. Engl. J. Med. 350, 2572-2581 (2004)

48. de Moel, E. C. et al. In RA, becoming seronegative over the first year of treatment does not translate to better chances of drug-free remission. Ann. Rheum. Dis. 77, 1836-1838 (2018)

49. Lochner, M. et al. Microbiota-induced tertiary lymphoid tissues aggravate inflammatory disease in the absence of RORgamma t and LTi cells. J. Exp. Med. 208, 125-134 (2011)

50. Harris, D. P. et al. Reciprocal regulation of polarized cytokine production by effector $B$ and $T$ cells. Nat. Immunol. 1, 475-482 (2000).
51. Wojciechowski, W. et al. Cytokine-producing effector B cells regulate type 2 immunity to $H$. polygyrus. Immunity 30, 421-433 (2009).

52. Menard, L. C. et al. B cells amplify IFN-gamma production by T cells via a TNF-alpha-mediated mechanism. J. Immunol. 179, 4857-4866 (2007).

53. Bao, Y. et al. Identification of IFN-gamma-producing innate B cells. Cell Res. 24, 161-176 (2014).

54. Barr, T. A., Brown, S., Mastroeni, P. \& Gray, D. TLR and $B$ cell receptor signals to $B$ cells differentially program primary and memory Th 1 responses to Salmonella enterica. J. Immunol. 185, 2783-2789 (2010).

55. Ganapamo, F., Dennis, V. A. \& Philipp, M. T. $\mathrm{CD} 19^{+}$cells produce IFN-gamma in mice infected with Borrelia burgdorferi. Eur. J. Immunol. 31 . 3460-3468 (2001).

56. Gjertsson, I., Foster, S. \& Tarkowski, A. Polarization of cytokine responses in B- and T-lymphocytes during Staphylococcus aureus infection. Microb. Pathog. 35 119-124 (2003).

57. Hart, G., Flaishon, L., Becker-Herman, S. \& Shachar, I. Tight regulation of IFN-gamma transcription and secretion in immature and mature $B$ cells by the inhibitory MHC class I receptor, Ly49G2. J. Immunol. 175, 5034-5042 (2005).

58. Yoshimoto, T., Okamura, H., Tagawa, Y. I., Iwakura, Y $\&$ Nakanishi, K. Interleukin 18 together with interleukin 12 inhibits IgE production by induction of interferon-gamma production from activated B cells Proc. Natl Acad. Sci. USA 94, 3948-3953 (1997).

59. Barr, T. A. et al. B cell depletion therapy ameliorates autoimmune disease through ablation of IL-6-producing B cells. J. Exp. Med. 209, 1001-1010 (2012).

60. Li, R. et al. Proinflammatory GM-CSF-producing $B$ cells in multiple sclerosis and B cell depletion therapy. Sci. Transl Med. 7, 310ra166 (2015). This study demonstrates that MBCs from patients with MS produce abnormal levels of GM-CSF, which acts on T cells and myeloid cells to amplify their proinflammatory potential. Moreover, anti-CD20 treatment of patients with MS normalized this abnormal B cell phenotype.

61. Rauch, P. J. et al. Innate response activator B cells protect against microbial sepsis. Science 335, 597-601 (2012)

62. Bermejo, D. A. et al. Trypanosoma cruzi trans-sialidase initiates a program independent of the transcription factors RORgammat and Ahr that leads to IL-17 production by activated B cells. Nat. Immunol. 14, 514-522 (2013)

63. Fritz, J. H. et al. Acquisition of a multifunctional $\lg \mathrm{A}^{+}$plasma cell phenotype in the gut. Nature $\mathbf{4 8 1}$, 199-203 (2011).

64. Njau, M. N. \& Jacob, J. Inducible nitric oxide synthase is crucial for plasma cell survival. Nat. Immunol. 15 219-221 (2014)

65. Saini, A. S., Shenoy, G. N., Rath, S., Bal, V. $\&$ George, A. Inducible nitric oxide synthase is a major intermediate in signaling pathways for the survival of plasma cells. Nat. Immunol. 15, 275-282 (2014).

66. Neumann, L. et al. Mucosal inducible NO synthaseproducing IgA+ plasma cells in helicobacter pyloriinfected patients. J. Immunol. 197, 1801-1808 (2016).

67. Cupi, M. L. et al. Plasma cells in the mucosa of patients with inflammatory bowel disease produce granzyme $\mathrm{B}$ and possess cytotoxic activities. J. Immunol. 192, 6083-6091 (2014).

68. Gordon, J. N. et al. Matrix metalloproteinase-3 production by gut IgG plasma cells in chronic inflammatory bowel disease. Inflamm. Bowel Dis. 14 195-203 (2008).

69. Mizoguchi, A., Mizoguchi, E., Takedatsu, H., Blumberg, R. S. \& Bhan, A. K. Chronic intestinal inflammatory condition generates IL-10-producing regulatory $B$ cell subset characterized by $C D 1 d$ upregulation. Immunity 16, 219-230 (2002).

70. Mangan, N. E. et al. Helminth infection protects mice from anaphylaxis via IL-10-producing $B$ cells J. Immunol. 173, 6346-6356 (2004).

71. Smits, H. H. et al. Protective effect of Schistosoma mansoni infection on allergic airway inflammation depends on the intensity and chronicity of infection J. Allergy Clin. Immunol. 120, 932-940 (2007).

72. Yanaba, K. et al. A regulatory $B$ cell subset with a unique $\mathrm{CD} 1 \mathrm{~d}^{\text {hi }} \mathrm{CD} 5$ + phenotype controls $\mathrm{T}$ celldependent inflammatory responses. Immunity $\mathbf{2 8}$, 639-650 (2008).

73. Yoshizaki, A. et al. Regulatory B cells control T-cell autoimmunity through IL-21-dependent cognate interactions. Nature 491, 264-268 (2012). 
74. Mauri, C., Gray, D., Mushtaq, N. \& Londei, M Prevention of arthritis by interleukin 10-producing B cells. J. Exp. Med. 197, 489-501 (2003).

75. Duddy, M. et al. Distinct effector cytokine profiles of memory and naive human B cell subsets and implication in multiple sclerosis. J. Immunol. 178 6092-6099 (2007).

76. Agrawal, S. \& Gupta, S. TLR1/2, TLR7, and TLR9 signals directly activate human peripheral blood naive and memory B cell subsets to produce cytokines, chemokines, and hematopoietic growth factors. J. Clin. Immunol. 31, 89-98 (2011).

77. Blair, P. A. et al. CD $19+C D 24^{\text {hi }} C D 38^{\text {hi }} B$ cells exhibit regulatory capacity in healthy individuals but are functionally impaired in systemic lupus erythematosus patients. Immunity 32, 129-140 (2010)

78. Shen, P. et al. IL-35-producing B cells are critical regulators of immunity during autoimmune and infectious diseases. Nature 507, 366-370 (2014).

79. Matsumoto, M. et al. Interleukin-10-producing plasmablasts exert regulatory function in autoimmune inflammation. Immunity 41, 1040-1051 (2014). Shen et al. (2014) and Matsumoto et al. (2014) show that PCs can produce anti-inflammatory cytokines such as IL-35 and IL-10, and that the production of these cytokines by PCs reduces the incidence and severity of EAE.

80. Rangaswamy, U. S. \& Speck, S. H. Murine gammaherpesvirus M2 protein induction of IRF4 via the NFAT pathway leads to IL-10 expression in B cells. PLoS Pathog. 10, e1003858 (2014).

81. Rojas, O. L. et al. Recirculating intestinal IgA-producing cells regulate neuroinflammation via IL-10. Cell 176 610-624.e18 (2019)

This study shows that mucosal IgA-producing PCs migrate to the inflamed CNS during EAE and suppress EAE in an IL-10-dependent manner. Moreover, this study shows that excess levels of BAFF and changes to the microbiota can augmen IgA-producing PCs, concomitant with a reduction in $\mathrm{EAE}$.

82. Rosser, E. C. et al. Regulatory B cells are induced by gut microbiota-driven interleukin- 1 beta and interleukin-6 production. Nat. Med. 20, 1334-1339 (2014).

83. Shen, P. \& Fillatreau, S. Antibody-independent functions of B cells: a focus on cytokines. Nat. Rev. Immunol 15, 441-451 (2015).

84. Machado-Santos, J. et al. The compartmentalized inflammatory response in the multiple sclerosis brain is composed of tissue-resident $\mathrm{CD} 8^{+} \mathrm{T}$ lymphocytes and B cells. Brain 141, 2066-2082 (2018).

85. Banchereau, R., Cepika, A. M., Banchereau, J. \& Pascual, V. Understanding human autoimmunity and autoinflammation through transcriptomics. Annu. Rev. Immunol. 35, 337-370 (2017).

86. Pisetsky, D. S. \& Lipsky, P. E. New insights into the role of antinuclear antibodies in systemic lupus erythematosus. Nat. Rev. Rheumatol. 16, 565-579 (2020).

87. Thien, M. et al. Excess BAFF rescues self-reactive $B$ cells from peripheral deletion and allows them to enter forbidden follicular and marginal zone niches. Immunity 20, 785-798 (2004).

88. Lesley, R. et al. Reduced competitiveness of autoantigen-engaged $B$ cells due to increased dependence on BAFF. Immunity 20, 441-453 (2004).

89. Mackay, F. et al. Mice transgenic for BAFF develop lymphocytic disorders along with autoimmune manifestations. J. Exp. Med. 190, 1697-1710 (1999).

90. Stohl, W. et al. B lymphocyte stimulator overexpression in patients with systemic lupus erythematosus: longitudinal observations. Arthritis Rheum. 48, 3475-3486 (2003).

91. Vincent, F. B., Morand, E. F., Schneider, P. Mackay, F. The BAFF/APRIL system in SLE pathogenesis. Nat. Rev. Rheumatol. 10, 365-373 (2014)

92. Mackay, F., Schneider, P., Rennert, P. \& Browning, J. BAFF AND APRIL: a tutorial on B cell survival. Annu. Rev. Immunol. 21, 231-264 (2003).

93. Furie, R. et al. A phase III, randomized, placebo-controlled study of belimumab, a monoclonal antibody that inhibits B lymphocyte stimulator, in patients with systemic lupus erythematosus. Arthritis Rheum. 63, 3918-3930 (2011).

94. Navarra, S. V. et al. Efficacy and safety of belimumab in patients with active systemic lupus erythematosus: a randomised, placebo-controlled, phase 3 trial. Lancet 377, 721-731 (2011).
95. Murphy, G. \& Isenberg, D. A. New therapies for systemic lupus erythematosus - past imperfect, future tense. Nat. Rev. Rheumatol. 15, 403-412 (2019).

96. Dorner, T. et al. Treatment of primary Sjogren's syndrome with ianalumab (VAY736) targeting B cells by BAFF receptor blockade coupled with enhanced, antibody-dependent cellular cytotoxicity. Ann. Rheum. Dis. 78, 641-647 (2019).

97. Rovin, B. H. et al. Efficacy and safety of rituximab in patients with active proliferative lupus nephritis: the Lupus Nephritis Assessment with Rituximab study. Arthritis Rheum. 64, 1215-1226 (2012).

98. Merrill, J. T. et al. Efficacy and safety of rituximab in moderately-to-severely active systemic lupus erythematosus: the randomized, double-blind, phase II/III systemic lupus erythematosus evaluation of rituximab trial. Arthritis Rheum. 62, 222-233 (2010).

99. Merrill, J. et al. Assessment of flares in lupus patients enrolled in a phase II/III study of rituximab (EXPLORER) Lupus 20, 709-716 (2011).

100. Lazarus, M. N., Turner-Stokes, T., Chavele, K. M. Isenberg, D. A. \& Ehrenstein, M. R. B-cell numbers and phenotype at clinical relapse following rituximab therapy differ in SLE patients according to anti-dsDNA antibody levels. Rheumatology 51, 1208-1215 (2012).

101. Banchereau, R. et al. Personalized immunomonitoring uncovers molecular networks that stratify lupus patients. Cell 165, 551-565 (2016).

102. Carter, L. M., Isenberg, D. A. \& Ehrenstein, M. R. Elevated serum BAFF levels are associated with rising anti-double-stranded DNA antibody levels and disease flare following $B$ cell depletion therapy in systemic lupus erythematosus. Arthritis Rheum. 65, 2672-2679 (2013).

103. Cambridge, G. et al. B cell depletion therapy in systemic lupus erythematosus: relationships among serum B lymphocyte stimulator levels, autoantibody profile and clinical response. Ann. Rheum. Dis. 67, 1011-1016 (2008)

104. Szili, D. et al. Suppression of innate and adaptive $B$ cell activation pathways by antibody coengagement of FcgammaRIlb and CD 19. mAbs 6, 991-999 (2014)

105. Forsthuber, T. G., Cimbora, D. M., Ratchford, J. N. Katz, E. \& Stuve, O. B cell-based therapies in CNS autoimmunity: differentiating CD19 and CD20 as therapeutic targets. Ther. Adv. Neurol. Disord. 11 1756286418761697 (2018).

106. Landsverk, O. J. et al. Antibody-secreting plasma cells persist for decades in human intestine. J. Exp. Med. 214, 309-317 (2017).

This work shows that mucosal PCs also lack CD1 9 and persist for decades in the host by using carbon-14 tracing.

107. Zhao, Q. Bispecific antibodies for autoimmune and inflammatory diseases: clinical progress to date. BioDrugs 34, 111-119 (2020).

108. Ginzler, E. M. et al. Atacicept in combination with MMF and corticosteroids in lupus nephritis: results of a prematurely terminated trial. Arthritis Res. Ther. 14 R33 (2012).

109. Sokolove, J. et al. Rheumatoid factor as a potentiator of anti-citrullinated protein antibody-mediated inflammation in rheumatoid arthritis. Arthritis Rheumatol. 66, 813-821 (2014).

110. Cohen, S. B. et al. Rituximab for rheumatoid arthritis refractory to anti-tumor necrosis factor therapy: results of a multicenter, randomized, double-blind, placebo-controlled, phase III trial evaluating primary efficacy and safety at twenty-four weeks. Arthritis Rheum. 54, 2793-2806 (2006)

111. Emery, P. \& Dorner, T. Optimising treatment in rheumatoid arthritis: a review of potential biological markers of response. Ann. Rheum. Dis. 70, 2063-2070 (2011)

112. Genovese, M. C., Kinnman, N., de La Bourdonnaye, G. Pena Rossi, C. \& Tak, P. P. Atacicept in patients with rheumatoid arthritis and an inadequate response to tumor necrosis factor antagonist therapy: results of a phase II, randomized, placebo-controlled, dose-finding trial. Arthritis Rheum. 63, 1793-1803 (2011).

113. Tak, P. P. et al. Atacicept in patients with rheumatoid arthritis: results of a multicenter, phase lb, doubleblind, placebo-controlled, dose-escalating, singleand repeated-dose study. Arthritis Rheum. 58, 61-72 (2008).

114. Corsiero, E. et al. Single cell cloning and recombinant monoclonal antibodies generation from RA synovial $B$ cells reveal frequent targeting of citrullinated histones of NETs. Ann. Rheum. Dis. 75, 1866-1875 (2016).
115. Humby, F. et al. Ectopic lymphoid structures support ongoing production of class-switched autoantibodies in rheumatoid synovium. PLoS Med. 6, e1 (2009).

116. Humby, F. et al. Synovial cellular and molecular signatures stratify clinical response to csDMARD therapy and predict radiographic progression in early rheumatoid arthritis patients. Ann. Rheum. Dis. 78 761-772 (2019)

117. Kavanaugh, A. et al. Assessment of rituximab's immunomodulatory synovial effects (ARISE trial). 1: clinical and synovial biomarker results. Ann. Rheum. Dis. 67, 402-408 (2008)

118. Thurlings, R. M. et al. Synovial tissue response to rituximab: mechanism of action and identification of biomarkers of response. Ann. Rheum. Dis. 67, 917-925 (2008).

119. Daien, C. I. et al. Regulatory B10 cells are decreased in patients with rheumatoid arthritis and are inversely correlated with disease activity. Arthritis Rheumatol. 66, 2037-2046 (2014).

120. Flores-Borja, F. et al. CD19+CD24 $4^{\text {hi }} C D 38^{\text {hi }} B$ cells maintain regulatory $\mathrm{T}$ cells while limiting $\mathrm{TH} 1$ and $\mathrm{TH} 17$ differentiation. Sci. Transl Med. 5, 173ra1 23 (2013).

121. Di Girolamo, N., Visvanathan, K., Lloyd, A. \& Wakefield, D. Expression of TNF-alpha by human plasma cells in chronic inflammation. J. Leukoc. Biol. 61, 667-678 (1997).

122. Yeo, L. et al. Cytokine mRNA profiling identifies $B$ cells as a major source of RANKL in rheumatoid arthritis. Ann. Rheum. Dis. 70, 2022-2028 (2011).

123. Winer, D. A. et al. B cells promote insulin resistance through modulation of $T$ cells and production of pathogenic IgG antibodies. Nat. Med. 17, 610-617 (2011).

124. Dingwell, L. S. et al. B-cell deficiency lowers blood pressure in mice. Hypertension 73, 561-570 (2019).

125. Chan, C. T. et al. Obligatory role for B cells in the development of angiotensin II-dependent hypertension. Hypertension 66, 1023-1033 (2015).

126. Luck, H. et al. Gut-associated IgA ${ }^{+}$immune cells regulate obesity-related insulin resistance. Nat. Commun. 10, 3650 (2019)

127. Adamo, L., Rocha-Resende, C. \& Mann, D. L. The emerging role of $B$ lymphocytes in cardiovascular disease. Annu. Rev. Immunol. 38, 99-121 (2020).

128. Zhang, L. \& Wang, Y. B lymphocytes in abdominal aortic aneurysms. Atherosclerosis 242, 311-317 (2015).

129. Sage, A. P., Tsiantoulas, D., Binder, C. J. \& Mallat, Z. The role of B cells in atherosclerosis. Nat. Rev. Cardiol. 16, 180-196 (2019)

130. Jackson, S. W. et al. Cutting edge: BAFF overexpression reduces atherosclerosis via $\mathrm{TACl}$-dependent $\mathrm{B}$ cell activation. J. Immunol. 197, 4529-4534 (2016).

131. Joly, P. et al. A single cycle of rituximab for the treatment of severe pemphigus. N. Engl. J. Med. 357 545-552 (2007)

132. van den Hoogen, L. L. \& van Laar, J. M. Targeted therapies in systemic sclerosis, myositis, antiphospholipid syndrome, and Sjogren's syndrome. Best Pract. Res. Clin. Rheumatol. 34, 101485 (2020).

133. Sharonov, G. V., Serebrovskaya, E. O., Yuzhakova, D. V. Britanova, O. V. \& Chudakov, D. M. B cells, plasma cells and antibody repertoires in the tumour microenvironment. Nat. Rev. Immunol. 20, 294-307 (2020).

134. Sabatino, J. J., Pröbstel, A.-K. \& Zamvil, S. S. B cells in autoimmune and neurodegenerative central nervous system diseases. Nat. Rev. Neurosci. 20, 728-745 (2019).

135. Lassmann, H. Pathogenic mechanisms associated with different clinical courses of multiple sclerosis. Front. Immunol. 9, 3116 (2018).

136. Sawcer, S. et al. Genetic risk and a primary role for cell-mediated immune mechanisms in multiple sclerosis. Nature 476, 214-219 (2011)

137. Serafini, B., Rosicarelli, B., Magliozzi, R., Stigliano, E. $\&$ Aloisi, F. Detection of ectopic B-cell follicles with germinal centers in the meninges of patients with secondary progressive multiple sclerosis Brain Pathol. 14, 164-174 (2004)

138. Zamvil, S. et al. T-cell clones specific for myelin basic protein induce chronic relapsing paralysis and demyelination. Nature 317, 355-358 (1985).

139. Kap, Y. S. et al. B-cell depletion attenuates white and gray matter pathology in marmoset experimental autoimmune encephalomyelitis. J. Neuropathol. Exp. Neurol. 70, 992-1005 (2011).

140. Kap, Y. S. et al. Late B cell depletion with a human anti-human CD20 IgG1 kappa monoclonal antibody halts the development of experimental autoimmune encephalomyelitis in marmosets. J. Immunol. 185 , 3990-4003 (2010). 
141. Sørensen, K. V. et al. The origin of cerebrospinal fluid somatostatin: hypothalamic or disperse centra nervous system secretion? Neuroendocrinology 32 , 335-338 (1981)

142. Obermeier, B. et al. Matching of oligoclonal immunoglobulin transcriptomes and proteomes of cerebrospinal fluid in multiple sclerosis. Nat. Med. 14, 688-693 (2008).

143. Lucchinetti, C. et al. Heterogeneity of multiple sclerosis lesions: Implications for the pathogenesis of demyelination. Ann. Neurol. 47, 707-717 (2000).

144. Bell, L., Lenhart, A., Rosenwald, A., Monoranu, C. M. $\&$ Berberich-Siebelt, F. Lymphoid aggregates in the CNS of progressive multiple sclerosis patients lack regulatory T cells. Front. Immunol. 10, 3090 (2019).

145. Compston, D. A. et al. Immunocytochemical localization of the terminal complement complex in multiple sclerosis. Neuropathol. Appl. Neurobiol. 15 307-316 (1989)

146. Gay, F. W., Drye, T. J., Dick, G. W. \& Esiri, M. M The application of multifactorial cluster analysis in the staging of plaques in early multiple sclerosis. Identification and characterization of the primary demyelinating lesion. Brain 120, 1461-1483 (1997)

147. Barnett, M. H., Parratt, J. D., Cho, E. S. \& Prineas, J. W. Immunoglobulins and complement in postmortem multiple sclerosis tissue. Ann. Neurol. 65, 32-46 (2009).

148. Guerrier, T. et al. Proinflammatory B-cell profile in the early phases of MS predicts an active disease Neurol. Neuroimmunol. Neuroinflamm 5, e431 (2017).

149. Li, R. et al. Proinflammatory GM-CSF-producing $B$ cells in multiple sclerosis and B cell depletion therapy. Sci. Transl Med. 7, 310 ra166 (2015)

150. Bar-Or, A. et al. Abnormal B-cell cytokine responses a trigger of T-cell-mediated disease in MS? Ann. Neurol. 67, 452-461 (2010).

151. Li, R., Patterson, K. R. \& Bar-Or, A. Reassessing B cell contributions in multiple sclerosis. Nat. Immunol. 19, 696-707 (2018)

152. Eggers, E. L. et al. Clonal relationships of CSF B cells in treatment-naive multiple sclerosis patients. JCI Insight 2, e92724 (2017).

153. Stern, J. N. H. et al. B cells populating the multiple sclerosis brain mature in the draining cervical lymph nodes. Sci. Transl Med. 6, 248ra107 (2014).

154. Howell, O. W. et al. Meningeal inflammation is widespread and linked to cortical pathology in multiple sclerosis. Brain 134, 2755-2771 (2011)

155. Magliozzi, R. et al. A Gradient of neuronal loss and meningeal inflammation in multiple sclerosis. Ann. Neurol. 68, 477-493 (2010).

156. Kappos, L. et al. A placebo-controlled trial of oral fingolimod in relapsing multiple sclerosis. $N$. Engl. J. Med. 362, 387-401 (2010)

157. Cohen, J. A. et al. Safety and efficacy of ozanimod versus interferon beta- $1 \mathrm{a}$ in relapsing multiple sclerosis (RADIANCE): a multicentre, randomised, 24-month, phase 3 trial. Lancet Neurol. 18, 1021-1033 (2019).

158. Polman, C. H. et al. A randomized, placebo-controlled trial of natalizumab for relapsing multiple sclerosis. N. Engl. J. Med. 354, 899-910 (2006).

159. Hauser, S. L. et al. B-cell depletion with rituximab in relapsing-remitting multiple sclerosis. $N$. Engl. J. Med. 358, 676-688 (2008)

160. Hauser, S. L. et al. Ocrelizumab versus interferon beta-1a in relapsing multiple sclerosis. $N$. Engl. J. Med. 376, 221-234 (2016).

Hauser et al. (2008) is the first clinical trial showing efficacy of BCDT (rituximab) in RRMS. The efficacy surpassed all expectations and was surprisingly fast ( 12 weeks after treatment). Although rituximab did not meet its primary end point for SPMS, Hauser et al. (2016) demonstrate that BCDT (ocrelizumab) is effective in PPMS.

161. Montalban, X. et al. Ocrelizumab versus placebo in primary progressive multiple sclerosis. N. Engl. J. Med. 376, 209-220 (2016)

162. Sorensen, P. S. et al. Safety and efficacy of ofatumumab in relapsing-remitting multiple sclerosis. A phase 2 study. Neurology 82, 573-581 (2014).

163. Hauser, S. L. et al. Ofatumumab versus teriflunomide in multiple sclerosis. N. Engl. J. Med. 383, 546-557 (2020).

164. Bar-Or, A. et al. Rituximab in relapsing-remitting multiple sclerosis: a 72-week, open-label, phase I trial. Ann. Neurol. 63, 395-400 (2008).

165. Cross, A. H., Stark, J. L., Lauber, J., Ramsbottom, M. J. \& Lyons, J.-A. Rituximab reduces B cells and T cells in cerebrospinal fluid of multiple sclerosis patients. J. Neuroimmunol. 180, 63-70 (2006).

166. Monson, N. L., Cravens, P. D., Frohman, E. M., Hawker, K. \& Racke, M. K. Effect of rituximab on the peripheral blood and cerebrospinal fluid B cells in patients with primary progressive multiple sclerosis. Arch. Neurol. 62, 258-264 (2005).

In spite of a reduction in clinical symptoms and depletion of B cells in the CSF, this study shows that oligoclonal bands in the CSF were unchanged following BCDT (rituximab) in patients with MS

167. Salzer, J. et al. Rituximab in multiple sclerosis. A retrospective observational study Safety efficacy. Neurology 87, 2074-2081 (2016)

168. PRISMS Study Group \& University of British Columbia MS/MRI Analysis Group. PRISMS-4: long-term efficacy of interferon- $\beta-1$ a in relapsing MS. Neurology 56 1628-1636 (2001).

169. Mayer, L. et al. Ocrelizumab infusion experience in patients with relapsing and primary progressive multiple sclerosis: results from the phase 3 randomized OPERA I, OPERA II, and ORATORIO studies. Mult. Scler. Relat. Disord. 30, 236-243 (2019)

170. Hawker, K. et al. Rituximab in patients with primary progressive multiple sclerosis: results of a randomized double-blind placebo-controlled multicenter trial. Ann. Neurol. 66, 460-471 (2009).

171. Fox, E. et al. A phase 2 multicenter study of ublituximab, a novel glycoengineered anti-CD20 monoclonal antibody, in patients with relapsing forms of multiple sclerosis. Mult. Scler. https://doi.org/ 10.1177/1352458520918375 (2020)

172. Bar-Or A et al Subcutaneous ofatumumab in patients with relapsing-remitting multiple sclerosis: the MIRROR study. Neurology 90, e1805-e1814 (2018).

173. Payandeh, $Z$. et al. The applications of anti-CD20 antibodies to treat various $B$ cells disorders. Biomed. Pharmacother. 109, 2415-2426 (2019).

174. Sawas, A. et al. A phase $1 / 2$ trial of ublituximab, a novel anti-CD20 monoclonal antibody, in patients with B-cell non-Hodgkin lymphoma or chronic lymphocytic leukaemia previously exposed to rituximab. Br. J. Haematol. 177, 243-253 (2017).

175. Herbst, R. et al. B-cell depletion in vitro and in vivo with an afucosylated anti-CD 19 antibody. J. Pharmacol. Exp. Ther. 335, 213-222 (2010).

176. Cepok, S. et al. Short-lived plasma blasts are the main $B$ cell effector subset during the course of multiple sclerosis. Brain 128, 1667-1676 (2005).

177. Agius, M. A. et al. Safety and tolerability of inebilizumab (MEDI-551), an anti-CD19 monoclonal antibody, in patients with relapsing forms of multiple sclerosis: results from a phase 1 randomised, placebo-controlled, escalating intravenous and subcutaneous dose study. Mult. Scler. 25, 235-245 (2019).

178. Montalban, X. et al. Placebo-controlled trial of an ora BTK inhibitor in multiple sclerosis. N. Engl. J. Med. 380, 2406-2417 (2019)

179. Di Paolo, J. A. et al. Specific Btk inhibition suppresses B cell- and myeloid cell-mediated arthritis. Nat. Chem Biol 7, 41-50 (2011)

180. Kappos, L. et al. Atacicept in multiple sclerosis (ATAMS): a randomised, placebo-controlled, double-blind, phase 2 trial. Lancet Neurol. 13 353-363 (2014).

This clinical trial aimed to reduce both B cells and PCs with atacicept treatment (TACI-immunoglobulin) on the basis of the reasonable hypothesis that collaboration of both B cell subsets conspires to cause MS pathology. However, the trial was halted prematurely due to deleterious effects of atacicept in patients with MS who experienced an increase in clinical symptoms in response to atacicept treatment. While unsuccessful, this trial obliges a rethinking of how different B cell subsets participate in MS pathogenesis.

181. Sergott, R. C. et al. ATON: results from a phase II randomized trial of the B-cell-targeting agent atacicept in patients with optic neuritis. J. Neurol. Sci. $\mathbf{3 5 1}$ 174-178 (2015)

182. $\mathrm{Xu}, \mathrm{Y}$. et al. Serum antibodies to 25 myelin oligodendrocyte glycoprotein epitopes in multiple sclerosis and neuromyelitis optica: clinical value for diagnosis and disease activity. Chin. Med. J. 125 3207-3210 (2012)

183. Khalil, M. et al. Epitope specificity of serum antibodies directed against the extracellular domain of myelin oligodendrocyte glycoprotein: Influence of relapses and immunomodulatory treatments. J. Neuroimmunol. 174, 147-156 (2006)
184. Devaux, B., Enderlin, F., Wallner, B. \& Smilek, D. E. Induction of $E A E$ in mice with recombinant human MOG, and treatment of EAE with a MOG peptide. J. Neuroimmunol. 75, 169-173 (1997)

185. Lyons, J. A., Ramsbottom, M. J. \& Cross, A. H. Critical role of antigen-specific antibody in experimental autoimmune encephalomyelitis induced by recombinant myelin oligodendrocyte glycoprotein. Eur. J. Immunol. 32, 1905-1913 (2002).

186. Galicia, G. et al. Isotype-switched autoantibodies are necessary to facilitate central nervous system autoimmune disease in $\mathrm{Aicda}^{-1-}$ and $\mathrm{Ung}^{-1-}$ mice. J. Immunol. 201, 1119-1130 (2018).

187. Haase, C. G. et al. The fine specificity of the myelin oligodendrocyte glycoprotein autoantibody response in patients with multiple sclerosis and normal healthy controls. J. Neuroimmunol. 114, 220-225 (2001).

188. Brandle, S. M. et al. Distinct oligoclonal band antibodies in multiple sclerosis recognize ubiquitous self-proteins. Proc. Natl Acad. Sci. USA 113 7864-7869 (2016)

189. Menge, T., von Büdingen, H. C., Lalive, P. H. \& Genain, C. P. Relevant antibody subsets against MOG recognize conformational epitopes exclusively exposed in solid-phase ELISA. Eur. J. Immunol. 37 , 3229-3239 (2007).

190. Ramanathan, S., Dale, R. C. \& Brilot, F. Anti-MOG antibody: the history, clinical phenotype, and pathogenicity of a serum biomarker for demyelination Autoimmun. Rev. 15, 307-324 (2016).

191. Lampasona, V. et al. Similar low frequency of anti-MOG IgC and IgM in MS patients and healthy subjects. Neurology 62, 2092-2094 (2004).

192. Ketelslegers, I. A. et al. Anti-MOG antibodies plead against MS diagnosis in an acquired demyelinating syndromes cohort. Mult. Scler. 21, 1513-1520 (2015).

193. Juryńczyk;czyk, M. et al. Brain lesion distribution criteria distinguish MS from AQP4-antibody NMOSD and MOG-antibody disease. J. Neurol. Neurosurg. Psychiatry 88, 132-136 (2017)

194. Reindl, M. \& Waters, P. Myelin oligodendrocyte glycoprotein antibodies in neurological disease. Nat. Rev. Neurol. 15, 89-102 (2019).

195. Mayer, M. C. et al. Distinction and temporal stability of conformational epitopes on myelin oligodendrocyte glycoprotein recognized by patients with different inflammatory central nervous system diseases. J. Immunol. 191, 3594-3604 (2013).

196. Rivas, J. R. et al. Peripheral VH4 ${ }^{+}$plasmablasts demonstrate autoreactive $\mathrm{B}$ cell expansion toward brain antigens in early multiple sclerosis patients. Acta Neuropathol. 133, 43-60 (2017).

197. Ligocki, A. J. et al. A distinct class of antibodies may be an indicator of gray matter autoimmunity in early and established relapsing remitting multiple sclerosis patients. ASN Neuro 7, 1759091415609613 (2015).

198. Blauth, K. et al. Antibodies produced by clonally expanded plasma cells in multiple sclerosis cerebrospinal fluid cause demyelination of spinal cord explants. Acta Neuropathol. 130, 765-781 (2015)

199. Willis, S. N. et al. Investigating the antigen specificity of multiple sclerosis central nervous system-derived immunoglobulins. Front. Immunol. 6, 600 (2015).

200. Quintana, F. J. et al. Antigen microarrays identify CNS-produced autoantibodies in RRMS. Neurology 78, 532-539 (2012)

201. Boronat, A et al. Analysis of antibodies to surface epitopes of contactin- 2 in multiple sclerosis. J. Neuroimmunol. 244, 103-106 (2012).

202. Reindl, M., Di Pauli, F., Rostásy, K. \& Berger, T. The spectrum of MOG autoantibody-associated demyelinating diseases. Nat. Rev. Neurol. 9, 455-461 (2013).

203. Fujihara, K. MOG-antibody-associated disease is different from MS and NMOSD and should be classified as a distinct disease entity - commentary. Mult. Scler. J. 26, 276-278 (2019).

204. Takai, Y. et al. Myelin oligodendrocyte glycoprotein antibody-associated disease: an immunopathological study. Brain 143, 1431-1446 (2020).

205. Cobo-Calvo, A. et al. Clinical spectrum and prognostic value of CNS MOG autoimmunity in adults: The MOGADOR study. Neurology 90, e1858-e1869 (2018).

206. Ramanathan, S. et al. Clinical course, therapeutic responses and outcomes in relapsing MOG antibody-associated demyelination. J. Neurol. Neurosurg. Psychiatry 89, 127-137 (2018).

207. Durozard, P. et al. Comparison of the response to rituximab between myelin oligodendrocyte glycoprotein and aquaporin-4 antibody diseases. Ann. Neurol. 87 256-266 (2020) 
208. Hacohen, Y. et al. Disease course and treatment responses in children with relapsing myelin oligodendrocyte glycoprotein antibody-associated disease. JAMA Neurol. 75, 478-487 (2018)

209. Whittam, D. H. et al. Treatment of MOG-IgGassociated disorder with rituximab: an international study of 121 patients. Mult. Scler. Relat. Disord. 44 102251 (2020)

210. Wingerchuk, D. M., Lennon, V. A., Lucchinetti, C. F., Pittock, S. J. \& Weinshenker, B. G. The spectrum of neuromyelitis optica. Lancet Neurol. 6, 805-815 (2007).

211. Lennon, V. A. et al. A serum autoantibody marker of neuromyelitis optica: distinction from multiple sclerosis. Lancet 364, 2106-2112 (2004).

212. Bruscolini, A. et al. Diagnosis and management of neuromyelitis optica spectrum disorders - an update. Autoimmun. Rev. 17, 195-200 (2018).

213. Hamid, S. H. M. et al. What proportion of AOP4-IgC negative NMO spectrum disorder patients are MOG-IgG positive? A cross sectional study of 132 patients. J. Neurol. 264, 2088-2094 (2017).

214. Mader, S. et al. Complement activating antibodies to myelin oligodendrocyte glycoprotein in neuromyelitis optica and related disorders. J. Neuroinflammation 8 184 (2011).

215. Cree, B. A. C. et al. Inebilizumab for the treatment of neuromyelitis optica spectrum disorder (N-MOmentum): a double-blind, randomised placebo-controlled phase 2/3 trial. Lancet 394, 1352-1363 (2019)

216. Kim, S. H. et al. Treatment outcomes with rituximab in 100 patients with neuromyelitis optica: influence of FCGR3A polymorphisms on the therapeutic response to rituximab. JAMA Neurol. 72, 989-995 (2015)

217. Dalmau, J. \& Graus, F. Antibody-mediated encephalitis. N. Engl. J. Med. 378, 840-851 (2018).

218. Prüss, H. et al. N-methyl-D-aspartate receptor antibodies in herpes simplex encephalitis. Ann. Neurol. 72, 902-911 (2012).

219. Dalmau, J. et al. Anti-NMDA-receptor encephalitis: case series and analysis of the effects of antibodies. Lancet Neurol. 7, 1091-1098 (2008).

220. Hughes, E. G. et al. Cellular and synaptic mechanisms of anti-NMDA receptor encephalitis. J. Neurosci. 30, 5866-5875 (2010)

221. Edwards, L. S., Barnett, M. H. \& Kiernan, M. C. 113 rituximab and maintenance mycophenolate mofetil for treatment of refractory anti-N-methylD-aspartate-receptor (NMDAR) encephalitis. J. Neurol. Neurosurg. Psychiatry 89, A44-A45 (2018)

222. Phillips, W. \& Vincent, A. Pathogenesis of myasthenia gravis: update on disease types, models, and mechanisms. F1000Res. 5, 1513 (2016).

223. Pascuzzi, R. M., Coslett, H. B. \& Johns, T. R. Longterm corticosteriod treatment of myasthenia gravis: report of 116 patients. Ann. Neurol. 15, 291-298 (1984).

224. Marino, M. et al. Long-lasting rituximab-induced reduction of specific-but not total-IgG4 in MuSK-positive myasthenia gravis. Front. Immunol. 11, 613 (2020).

225. Diaz-Manera, J. et al. Long-lasting treatment effect of rituximab in MuSK myasthenia. Neurology 78 189-193 (2012).

226. van der Neut Kolfschoten, M. et al. Anti-inflammatory activity of human IgG4 antibodies by dynamic Fab arm exchange. Science 317, 1554-1557 (2007).

227. Huijbers, M. G., Plomp, J. J., van der Maarel, S. M. \& Verschuuren, J. J. IgG4-mediated autoimmune diseases: a niche of antibody-mediated disorders. Ann. NY Acad. Sci. 1413, 92-103 (2018)

228. Stathopoulos, P., Kumar, A., Nowak, R. J. \& O'Connor, K. C. Autoantibody-producing plasmablasts after B cell depletion identified in muscle-specific kinase myasthenia gravis. JCI Insight 2, e94263 (2017).

229. Reddy, V. et al. Obinutuzumab induces superior B-cell cytotoxicity to rituximab in rheumatoid arthritis and systemic lupus erythematosus patient samples. Rheumatology 56, 1227-1237 (2017).

230. Ivanov, A. et al. Monoclonal antibodies directed to CD20 and HLA-DR can elicit homotypic adhesion followed by lysosome-mediated cell death in human lymphoma and leukemia cells. J. Clin. Invest. 119 , 2143-2159 (2009)

231. Kumar, A., Planchais, C., Fronzes, R., Mouquet, H. $\Sigma$ Reyes, N. Binding mechanisms of therapeutic antibodies to human CD20. Science 369, 793-799 (2020).

232 Gelfand, J. M., Cree, B. A. C. \& Hauser, S. L. Ocrelizumab and other CD20+ B-cell-depleting therapies in multiple sclerosis. Neurotherapeutics $\mathbf{1 4}$, 835-841 (2017)
233. Moore, G. L., Chen, H., Karki, S. \& Lazar, G. A. Engineered Fc variant antibodies with enhanced ability to recruit complement and mediate effector functions. $m A b s$ 2, 181-189 (2010).

234. Chan, H. T. et al. CD20-induced lymphoma cell death is independent of both caspases and its redistribution into triton X-100 insoluble membrane rafts. Cancer Res. 63, 5480-5489 (2003).

235. Lim, S. H. et al. Fc gamma receptor Ilb on target $B$ cells promotes rituximab internalization and reduces clinical efficacy. Blood 118, 2530-2540 (2011).

236. Teeling, J. L. et al. The biological activity of human CD20 monoclonal antibodies is linked to unique epitopes on CD20. J. Immunol. 177, 362-371 (2006).

237. Martin Mdel, P. et al. Depletion of B lymphocytes from cerebral perivascular spaces by rituximab. Arch. Neurol. 66, 1016-1020 (2009).

238. Esfandi, S., Salimian, S., Corboy, J. \& Alvarez, E. Persistent $\mathrm{B}$ lymphocytes in multiple sclerosis plaques after rituximab treatment (P5.341). Neurology $\mathbf{8 8}$ (Suppl. 16), P5.341 (2017).

239. Touil, H. et al. Human central nervous system astrocytes support survival and activation of B cells: implication for MS pathogenesis. J. Neuroinflammation 15, 114 (2018).

240. Mei, H. E. et al. A unique population of IgG-expressing plasma cells lacking CD19 is enriched in human bone marrow. Blood 125, 1739-1748 (2015).

This article shows that LLPCs in the bone marrow lack CD19 expression.

241. Maude, S. L. et al. Chimeric antigen receptor T cells for sustained remissions in leukemia. N. Engl. J. Med. 371, 1507-1517 (2014).

242. Bhoj, V. G. et al. Persistence of long-lived plasma cells and humoral immunity in individuals responding to CD19-directed CAR T-cell therapy. Blood 128, 360-370 (2016)

243. Hale, M., Rawlings, D. J. \& Jackson, S. W. The long and the short of it: insights into the cellular source of autoantibodies as revealed by B cell depletion therapy. Curr. Opin. Immunol. 55, 81-88 (2018).

244. Cambridge, G. et al. The effect of B-cell depletion therapy on serological evidence of B-cell and plasmablast activation in patients with rheumatoid arthritis over multiple cycles of rituximab treatment. J. Autoimmun. 50, 67-76 (2014).

245. Pellkofer, H. L. et al. Long-term follow-up of patients with neuromyelitis optica after repeated therapy with rituximab. Neurology 76, 1310-1315 (2011).

246. Bingham, C. O. 3rd et al. Immunization responses in rheumatoid arthritis patients treated with rituximab: results from a controlled clinical trial. Arthritis Rheum. 62, 64-74 (2010).

247. Li, R. et al. Cytokine-defined B cell responses as therapeutic targets in multiple sclerosis. Front Immunol. 6, 626 (2015)

248. Molnarfi, N. et al. MHC class II-dependent B cell APC function is required for induction of CNS autoimmunity independent of myelin-specific antibodies. J. Exp. Med. 210, 2921-2937 (2013).

249. Weber, M. S. et al. B-cell activation influences T-cell polarization and outcome of anti-CD20 B-cell depletion in central nervous system autoimmunity. Ann. Neurol. 68, 369-383 (2010).

250. Constant, S. et al. Peptide and protein antigens require distinct antigen-presenting cell subsets for the priming of CD4+ T cells. J. Immunol. 154 4915-4923 (1995).

251. Jelcic, I. et al. Memory B cells activate brain-homing autoreactive $\mathrm{CD}^{+} \mathrm{T}$ cells in multiple sclerosis. Cell 175, 85-100 e123 (2018).

252. Hultin, L. E., Hausner, M. A., Hultin, P. M. \& Giorgi, J. V. CD20 (pan-B cell) antigen is expressed at a low level on a subpopulation of human T lymphocytes. Cytometry 14, 196-204 (1993).

253. Eggleton, P et al. Frequency of Th17 CD20+ cells in the peripheral blood of rheumatoid arthritis patients is higher compared to healthy subjects. Arthritis Res. Ther. 13, R208 (2011).

254. von Essen, M. R. et al. Proinflammatory CD20+ T cells in the pathogenesis of multiple sclerosis. Brain 142 120-132 (2019)

255. Palanichamy, A. et al. Rituximab efficiently depletes increased CD20-expressing T cells in multiple sclerosis patients. J. Immunol. 193, 580-586 (2014).

256. Sabatino, J. J. Jr. et al. Anti-CD20 therapy depletes activated myelin-specific CD8 ${ }^{+} \mathrm{T}$ cells in multiple sclerosis. Proc. Natl Acad. Sci. USA 116 25800-25807 (2019).
257. Jiang, R. et al. Single-cell repertoire tracing identifies rituximab refractory $\mathrm{B}$ cells during myasthenia gravis relapses. JCI Insight 5, e136471 (2020).

258. Krumbholz, M. et al. BAFF is produced by astrocytes and up-regulated in multiple sclerosis lesions and primary central nervous system lymphoma. J. Exp. Med. 201, 195-200 (2005).

259. Ragheb, S. et al. Multiple sclerosis: BAFF and CXCL13 in cerebrospinal fluid. Mult. Scler. 17, 819-829 (2011)

260. Steri, M. et al. Overexpression of the cytokine BAFF and autoimmunity risk. N. Engl. J. Med. 376 1615-1626 (2017).

261. Kannel, K. et al. Changes in blood B cell-activating factor (BAFF) levels in multiple sclerosis: a sign of treatment outcome. PLoS ONE 10, e0143393 (2015).

262. Benson, M. J. et al. Cutting edge: the dependence of plasma cells and independence of memory B cells on BAFF and APRIL. J. Immunol. 180, 3655-3659 (2008).

263. Mei, H. E. et al. Steady-state generation of mucosal $\lg \mathrm{A}^{+}$plasmablasts is not abrogated by B-cell depletion therapy with rituximab. Blood 116, 5181-5190 (2010).

264. Chittasupho, C., Siahaan, T. J., Vines, C. M. \& Berkland, C. Autoimmune therapies targeting costimulation and emerging trends in multivalent therapeutics. Ther. Deliv. 2, 873-889 (2011).

265. Edner, N. M., Carlesso, G., Rush, J. S. \& Walker, L. S. K. Targeting co-stimulatory molecules in autoimmune disease. Nat. Rev. Drug Discov. 19, 860-883 (2020).

266. Huang, W. et al. The effect of anti-CD40 ligand antibody on $B$ cells in human systemic lupus erythematosus. Arthritis Rheum. 46, 1554-1562 (2002).

267. Lai, J. H., Luo, S. F. \& Ho, L. J. Targeting the CD40-CD 154 signaling pathway for treatment of autoimmune arthritis. Cells 8, 927 (2019)

268. Karnell, J. L., Rieder, S. A., Ettinger, R. \& Kolbeck, R. Targeting the CD40-CD40L pathway in autoimmune diseases: humoral immunity and beyond. Adv. Drug Deliv. Rev. 141, 92-103 (2019).

269. Soni, C. et al. Plasmacytoid dendritic cells and type I interferon promote extrafollicular B cell responses to extracellular self-DNA. Immunity 52, 1022-1038.e7 (2020).

270. Morand, E. F. et al. Trial of anifrolumab in active systemic lupus erythematosus. N. Engl. J. Med. 382, 211-221 (2020)

271. Lino, A. C. et al. LAG-3 inhibitory receptor expression identifies immunosuppressive natural regulatory plasma cells. Immunity 49, 120-133.e9 (2018).

272. Yang, C. et al. Fecal IgA levels are determined by strain-level differences in bacteroides ovatus and are modifiable by gut microbiota manipulation. Cell Host Microbe 27, 467-475.e6 (2020).

273. Tan, J. et al. A LAIR1 insertion generates broadly reactive antibodies against malaria variant antigens. Nature 529, 105-109 (2016)

274. Murugan, R. et al. Clonal selection drives protective memory $\mathrm{B}$ cell responses in controlled human malaria infection. Sci. Immunol. 3, eaap8029 (2018).

275. Pikor, N. B. et al. Remodeling of light and dark zone follicular dendritic cells governs germinal center responses. Nat. Immunol. 21, 649-659 (2020).

276. Sabouri, Z. et al. Redemption of autoantibodies on anergic $B$ cells by variable-region glycosylation and mutation away from self-reactivity. Proc. Natl Acad. Sci. USA 111, E2567-E2575 (2014).

277. Halverson, R., Torres, R. M. \& Pelanda, R. Receptor editing is the main mechanism of $B$ cell tolerance toward membrane antigens. Nat. Immunol. 5, 645-650 (2004)

278. Wardemann, H. et al. Predominant autoantibody production by early human B cell precursors. Science 301, 1374-1377 (2003)

279. Palanichamy, A. et al. Novel human transitional $\mathrm{B}$ cell populations revealed by $\mathrm{B}$ cell depletion therapy. J. Immunol. 182, 5982-5993 (2009).

280. Griffin, D. O., Holodick, N. E. \& Rothstein, T. L. Human B1 cells in umbilical cord and adult peripheral blood express the novel phenotype $C D 20^{+} \mathrm{CD} 27^{+} \mathrm{CD} 43^{+} \mathrm{CD} 70$ J. Exp. Med. 208, 67-80 (2011).

281. Descatoire, M., Weill, J. C., Reynaud, C. A. \& Weller, S. A human equivalent of mouse B-1 cells? J. Exp. Med. 208, 2563-2564 (2011).

282. Quach, T. D. et al. Distinctions among circulating antibody-secreting cell populations, including B-1 cells, in human adult peripheral blood. J. Immunol. 196, 1060-1069 (2016)

283. Phan, T. G., Green, J. A., Gray, E. E., Xu, Y. \& Cyster, J. G. Immune complex relay by subcapsular sinus macrophages and noncognate $B$ cells drives antibody affinity maturation. Nat. Immunol. 10 786-793 (2009). 
284. Phan, T. G., Grigorova, I., Okada, T. \& Cyster, J. G. Subcapsular encounter and complement-dependent transport of immune complexes by lymph node B cells. Nat. Immunol. 8, 992-1000 (2007).

285. Heesters, B. A. et al. Endocytosis and recycling of immune complexes by follicular dendritic cells enhances B cell antigen binding and activation. Immunity 38, 1164-1175 (2013)

286. Gatto, D., Wood, K. \& Brink, R. EBI2 operates independently of but in cooperation with CXCR5 and CCR7 to direct B cell migration and organization in follicles and the germinal center. J. Immunol. 187 4621-4628 (2011)

287. Hannedouche, S. et al. Oxysterols direct immune cell migration via EBI2. Nature 475, 524-527 (2011)

288. Pereira, J. P., Kelly, L. M., Xu, Y. \& Cyster, J. G. EBI2 mediates $B$ cell segregation between the outer and centre follicle. Nature 460, 1122-1126 (2009).

289. Green, J. A. et al. The sphingosine 1-phosphate receptor $\mathrm{S}_{1} \mathrm{P}_{2}$ maintains the homeostasis of germinal center $\mathrm{B}$ cells and promotes niche confinement. Nat. Immunol. 12, 672-680 (2011)

290. Muppidi, J. R., Lu, E. \& Cyster, J. G. The G protein coupled receptor P2RY8 and follicular dendritic cells promote germinal center confinement of B cells, whereas S1PR3 can contribute to their dissemination. J. Exp. Med. 212, 2213-2222 (2015).
291. Fecteau, J. F., Cote, G. \& Neron, S. A new memory $C D 27-\operatorname{lgG}+B$ cell population in peripheral blood expressing $\mathrm{VH}$ genes with low frequency of somatic mutation. J. Immunol. 177, 3728-3736 (2006).

292. Ehrhardt, G. R. et al. Expression of the immunoregulatory molecule FcRH4 defines a distinctive tissue-based population of memory B cells. J. Exp. Med. 202, 783-791 (2005).

293. Moir, S. et al. Evidence for HIV-associated B cell exhaustion in a dysfunctional memory B cell compartment in HIV-infected viremic individuals. J. Exp. Med. 205, 1797-1805 (2008).

294. Sullivan, R. T. et al. FCRL5 delineates functionally impaired memory B cells associated with plasmodium falciparum exposure. PLoS Pathog. 11, e1004894 (2015).

295. Zuccarino-Catania, G. V. et al. CD80 and PD-L2 define functionally distinct memory B cell subsets that are independent of antibody isotype. Nat. Immunol. 15 631-637 (2014)

296. Krishnamurty, A. T. et al. Somatically hypermutated plasmodium-specific lgM+ memory B cells are rapid plastic, early responders upon malaria rechallenge. Immunity 45, 402-414 (2016).

297. Seifert, M. et al. Functional capacities of human IgM memory B cells in early inflammatory responses and secondary germinal center reactions. Proc. Natl Acad. SCi. USA 112, E546-E555 (2015).

\section{Acknowledgements}

The authors thank J. Browning (Boston University) for his critical reading of the manuscript as well as M. Cancro (University of Pennsylvania), M. Pepper (University of Washington) and F. Lund (University of Alabama) for helpful discussions. They also acknowledge the funding support from the MS Society of Canada for their research on plasma cell activity in experimental autoimmune encephalomyelitis and multiple sclerosis (grant no. 3194).

\section{Author contributions}

The authors contributed equally to all aspects of the article.

\section{Competing interests}

J.L.G. performed consulting for Roche on anti-CD20 in multiple sclerosis in 2019 and received funding for research on the impact of anti-CD20 in experimental autoimmune encephalomyelitis (Roche) and sphingosine 1-phosphate receptor 1 inhibitors in experimental autoimmune encephalomyelitis (Novartis). These interests did not influence the content of this Review. The other authors declare no competing interests.

\section{Publisher's note}

Springer Nature remains neutral with regard to jurisdictional claims in published maps and institutional affiliations.

(c) Springer Nature Limited 2020 